ISSN 0819-2642

ISBN 0734025505

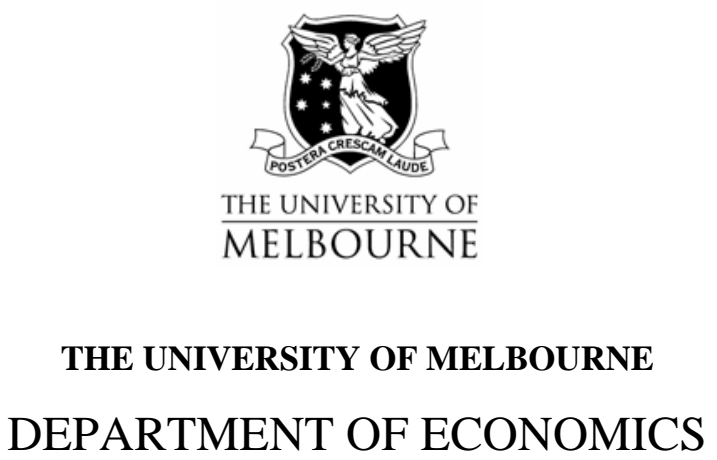

RESEARCH PAPER NUMBER 894

OCTOBER 2004

OPTIMAL LICENSING POLICY IN

DIFFERENTIATED INDUSTRIES

by

Nisvan Erkal

Department of Economics

The University of Melbourne

Melbourne Victoria 3010

Australia. 


\title{
Optimal Licensing Policy in Differentiated Industries*
}

\author{
Nisvan Erkal ${ }^{\dagger}$ \\ University of Melbourne \\ First version: April 2000 \\ This version: October 2004
}

\begin{abstract}
This paper analyses the policy implications of licensing between producers of differentiated goods. We consider and compare two-part tariff, fixed fee, royalty and collusive licensing contracts. Under the optimal licensing policy, there will be no technology transfers if the innovation size is sufficiently small and degree of product differentiation is sufficiently low. On the other hand, licensing deals that involve drastic innovations are always socially desirable. In the limit, as product differentiation converges to zero, it becomes socially desirable to transfer drastic innovations only. The range of innovation sizes that is socially optimal to transfer increases as product differentiation increases.
\end{abstract}

JEL Classification: D4; L41; O38

Keywords: Patent licensing, product differentiation, antitrust policy

\footnotetext{
*This paper is based on the first chapter of my dissertation (University of Maryland, College Park, 2002). I am grateful to Rachel Kranton, Dan Vincent, Larry Ausubel, Egemen Tanin, John Creedy, Harry Bloch, two referees, and seminar participants at the University of Melbourne and the University of Sydney for their valuable comments.

${ }^{\dagger}$ Department of Economics, University of Melbourne, Victoria 3010, Australia. E-mail: n.erkal@unimelb.edu.au.
} 


\section{Introduction}

In many industries, licensing plays an important role in decisions regarding the development and commercialization of innovations. ${ }^{1}$ The goal of this paper is to analyze the policy implications of licensing arrangements between competing firms. In spite of the fact that innovators may gain significant market power, it is common for technology transfer deals to take place between competitors. In such cases, licensing of intellectual property raises complex antitrust issues. On the one hand, the diffusion of new technologies potentially increases the benefits consumers can obtain from the use of those innovations. On the other hand, the licensing arrangements firms use to exchange their technologies may have anticompetitive and welfare-reducing consequences. Thus, while patent licensing plays an important role in the dissemination of innovations within an industry, it is necessary to compare the private and social incentives to license.

We consider licensing of cost-reducing innovations between firms producing in a differentiated duopoly. If the firms are horizontal competitors, the licensor faces a trade-off between increased rivalry and increased licensing revenues while making its licensing decision. We explore how restrictive a licensing policy the government should have in different types of industries and whether there are cases when it is socially optimal not to have any technology transfers. In addition, we determine whether it may be socially desirable to allow collusive licensing agreements where firms fix prices.

Antitrust authorities in different countries have recently started to take actions to determine how they will deal with the antitrust implications of licensing arrangements. In the United States, the "Antitrust Guidelines for the Licensing of Intellectual Property" issued jointly by the Department of Justice (DOJ) and the Federal Trade Commission (FTC) in 1995 describe generally how the agencies will handle various forms of licensing deals that may contain anticompetitive provisions. ${ }^{2}$ As pointed out in the Guidelines, such anticompetitive provisions are especially worrisome when the technology transfer takes place between

\footnotetext{
${ }^{1}$ Degnan (1999) reports that royalties and fees collected by U.S. corporations exceeded $\$ 136$ billion in 1996. Anand and Khanna (2000) document that licensing accounted for $38 \%$ of all strategic alliances in the chemical industry, $18 \%$ of all strategic alliances in the computer industry, and $24 \%$ of all strategic alliances in the electronics industry between 1990 and 1993. A study by Grindley and Teece (1997) documents that major firms in high-technology industries, such as AT\&T, IBM, Texas Instruments, and Hewlett-Packard, regard the use of licensing and cross-licensing as an important part of their business strategies. Arora and Fosfuri (1998), and Grindley and Nickerson (1996) discuss the extensive use of licensing in the chemical industry.

${ }^{2}$ Gilbert and Shapiro (1997) contains a discussion of the history of antitrust enforcement in the licensing of intellectual property.
} 
horizontal competitors. The general approach stated in the Guidelines is that such provisions will not be challenged as long as they are "necessary to achieve procompetitive benefits that outweigh... [the] anticompetitive effects (p. 12)." Moreover, it is stated that certain kinds of licensing restraints, such as naked price fixing, are so "plainly anticompetitive" that they should be treated as unlawful "without an elaborate inquiry into the restraints' likely competitive effect (p. 16)."

In contrast, we find that there may be cases when price fixing is socially preferable to other types of licensing contracts and to no licensing. This is true both in case of drastic and nondrastic innovations. Our analysis is also significant in the light of recent policy considerations in Australia regarding the antitrust treatment of licensing arrangements. In Australia, Part IV of the Trade Practices Act 1974, administered by the Australian Competition and Consumer Commission (ACCC), deals with anti-competitive practices. Currently, licensing arrangements of the kind considered in this paper are exempt from the Act. ${ }^{3}$ However, the government has recently decided to expose terms and conditions of licensing arrangements to Part IV of the Act to a greater extent. Specifically, the Final Report of the Intellectual Property and Competition Review Committee, submitted in September 2000, recommends that "the exemption ... be amended to remove protection for price and quantity restrictions and for horizontal agreements." ${ }^{4}$ As a response to the Final Report, the ACCC is currently in the process of coming up with some guidelines regarding its treatment of licensing arrangements.

To analyze the policy implications of licensing arrangements, we consider industries where firms predominantly use royalty, fixed fee or two-part tariff licensing contracts. As shown in Rockett (1990b), in industries where imitation is not costly and is likely to take place, firms may prefer to use fixed fee licensing contracts only. ${ }^{5,6}$ On the other hand, Gallini and Wright (1990), Beggs (1992), Macho-Stadler et al. (1996), and Choi (2001) show that the existence of asymmetric information may cause the firms to prefer royalty payments. ${ }^{7,8}$ We assume

\footnotetext{
${ }^{3}$ This is stated in s. 51(3) of the Trade Practices Act.

${ }^{4}$ See p. 202 of the Final Report available at http://www.ipcr.gov.au/.

${ }^{5}$ Rockett (1990) assumes that the fixed fee is paid up front. The licensees may have incentives to imitate the technology to avoid making royalty payments if imitation is technologically feasible and not too costly. This may cause the licensor to put much more weight on fixed fees than on royalties.

${ }^{6}$ High monitoring costs may be another reason for the use of fixed fee licensing contracts only.

${ }^{7}$ Gallini and Wright (1990) and Beggs (1992) consider cases when either the licensor or the licensee has more information about the value of the innovation. In their models, royalties may be used as a signalling device by the more knowledgeable party. In Choi (2001), royalty payments may be used to encourage the licensor to transfer a sufficient amount of information in an environment of incomplete contracts.

${ }^{8}$ Examining a sample of international licensing contracts signed by Spanish firms in 1991, Macho-Stadler et al. (1996) state that most of the contracts were based on either fixed fees or royalty payments only. According to a survey done among 150 U.S. corporations, Rostoker (1984) states that $46 \%$ of the firms surveyed used
} 
that if collusive licensing deals are allowed by the antitrust authorities, the firms will always prefer them over the other types of licensing deals.

While a fixed fee has no effect on the behavior of the licensee, a royalty affects the licensee's output choice since it increases the (effective) marginal cost of production. As a result, royalties can act as a facilitating device. We find that if the licensing agreement includes a royalty rate only, collusive licensing may be more attractive than royalty licensing in two ways. First, a large set of technology transfers that are socially desirable under royalty licensing result in even a higher welfare increase under collusive licensing. That is, allowing the firms to have a direct control over each other's prices through collusive licensing may result in a higher welfare level than allowing the licensor to have an indirect control over the price of the rival firm through licensing with a royalty. Second, some technology transfers that may not be socially desirable under royalty licensing become socially desirable if the firms use a collusive licensing deal.

In general, the results on optimal licensing policy reveal that for sufficiently low degrees of product differentiation and sufficiently small innovations, it is socially optimal to have no technology transfers at all. This is because licensing deals between producers of close substitutes that involve sufficiently small (nondrastic) innovations are socially desirable if and only if the firms use fixed fee licensing. However, the firms do not find it optimal to use fixed fee licensing for sufficiently high innovation sizes and low degrees of differentiation.

Under the optimal licensing policy, the range of innovation sizes that is socially desirable to transfer decreases as the degree of product differentiation decreases. In the limit, as the degree of product differentiation converges to zero, it is optimal to transfer drastic innovations only. In fact, if the innovation is drastic, it is always socially desirable to encourage its transfer. In industries where firms choose to do royalty licensing only, it is socially preferable to have such transfers by means of collusive licensing deals. That is, welfare under collusive licensing is higher than welfare under royalty licensing which is higher than welfare under no licensing. In industries where fixed fee licensing is preferred, it is socially optimal to allow collusive licensing deals for drastic innovations between producers of close substitutes, which would otherwise choose not to have any technology transfers.

There exists a vast theoretical literature exploring the reasons, types, and consequences of technology licensing. Kamien (1992) contains a survey. The papers in this literature can be grouped into two depending on whether they assume the licensor and the potential licensees two-part-tariff licensing, 39\% used royalty licensing, and 13\% used fixed-fee licensing. 
operate in different markets or in the same market. ${ }^{9}$ Among the papers in the second group, Katz and Shapiro (1985) and Marjit (1990) consider fixed fee licensing between Cournot duopolists producing homogenous products and conclude that major innovations will not be licensed. Katz and Shapiro (1985) also show that the social incentives to license exceed the private ones. Our analysis shows that this result holds only in industries characterized by high rates of imitation where the firms prefer to do fixed fee licensing only. Rockett (1990b) shows that whether royalty or fixed fee licensing will be used depends on the likelihood of imitation. Wang (1998 and 2002), and Wang and Yang (1999) show that royalty licensing may be more profitable than fixed fee licensing in a Cournot and Bertrand duopoly respectively. Kamien and Tauman (2002) extend Wang (1998) to the case of a Cournot oligopoly. Finally, in a recent paper, Fauli-Oller and Sandonis (2002) show that licensing deals between producers of differentiated products may be welfare-reducing. ${ }^{10}$

Among the papers that analyze the antitrust implications of licensing between rival firms, Shapiro (1985) and Lin (1996) discuss how two-part tariff and fixed fee licensing contracts can be designed to achieve collusion. Gallini (1984), Rockett (1990), Eswaran (1994), and Hollis (2002) show how firms can shape the competition they face by strategically choosing the types of firms they license their technology to. Recently, Fauli-Oller and Sandonis (2003) analyze when licensing may be welfare-superior to a merger. Although their treatment of mergers is similar to our treatment of collusive licensing deals, this paper differs by having a more general analysis of optimal licensing policy. We discuss when it is socially optimal to have the different types of licensing contracts and what types of innovations are socially optimal to transfer. Our results differ by showing how restrictive a licensing policy the government should have in different types of industries.

The paper proceeds as follows. Section II provides an outline of the model. In Section III, we start the analysis by finding the profit levels under no licensing. Section IV contains an analysis of firms' private incentives to license. For expositional ease, we first consider the special cases of royalty and fixed fee licensing before turning to the general case of two-part tariff licensing. In this section, we also present the outcome under collusive licensing. The main results of the paper regarding optimal licensing policy are in Section V. Section VI

\footnotetext{
${ }^{9}$ For the first group of papers, see, for example, Katz and Shapiro (1986), Kamien and Tauman (1986), Kamien, Oren and Tauman (1992), and Muto (1993). See Poddar and Sinha (2004) for a comparison of the optimal licensing strategies of an insider and an outsider licensor.

${ }^{10}$ All of the papers we refer to here focus on licensing deals between actual competitors. See Gallini (1984), Shepard (1987), Rockett (1990a) and Arora and Fosfuri (2003) for an analysis of licensing deals between incumbents and potential competitors.
} 
concludes and indicates directions for future research. All proofs are in the Appendix.

\section{Model}

There are two firms, firm $i$ and firm $j$, each producing a differentiated good. The firms have constant marginal costs of production, $c_{i}$ and $c_{j}$. Firm $i$ is the patentholder for a process technology that enables it to have a lower marginal cost than firm $j .{ }^{11}$ Letting $\varepsilon$ represent the size of the innovation, we have $c_{j}=c_{i}+\varepsilon$. Firm $i$ can license the technology to firm $j$ in return for a payment, in which case both firms face a marginal cost of $c_{i}$.

Following Singh and Vives (1984), we consider the following differentiated duopoly model. ${ }^{12}$ There is a continuum of consumers of the same type with a utility function that is separable in income. The representative consumer maximizes $U\left(q_{i}, q_{j}\right)-p_{i} q_{i}-p_{j} q_{j}$, where $p_{i}$ and $q_{i}$ stand for the price and output level of firm $i$ respectively. $U\left(q_{i}, q_{j}\right)$ is assumed to be quadratic, strictly concave in $q_{i}$ and $q_{j}$, and symmetric with respect to $q_{i}$ and $q_{j}$. It is defined as

$$
U\left(q_{i}, q_{j}\right)=a\left(q_{i}+q_{j}\right)-\left(q_{i}^{2}+2 \theta q_{i} q_{j}+q_{j}^{2}\right) / 2
$$

where $a>0$ and $1-\theta>0$. The parameter $\theta$ expresses the degree of product differentiation. The goods are substitutes, independent, or complements according to whether $\theta>0, \theta=0$, or $\theta<0$. Given this utility function, the direct demand functions are

$$
q_{i}=\frac{a(1-\theta)-p_{i}+\theta p_{j}}{\left(1-\theta^{2}\right)} ; \quad q_{j}=\frac{a(1-\theta)-p_{j}+\theta p_{i}}{\left(1-\theta^{2}\right)} .
$$

These demand functions are downward-sloping in own prices and are increasing (decreasing) functions of the price of the rival's product if the goods are substitutes (complements). In the following analysis, we restrict attention to the case of producers of substitute goods, $0 \leq \theta<1 .{ }^{13}$ Moreover, since the demand functions are not defined for the case of $\theta=1$, we will not be analyzing the case of perfect substitutes.

The two firms and the antitrust authorities play the following multi-stage noncooperative game. In the first stage, the antitrust authorities announce their policy regarding the licensing of intellectual property. In the second stage, following the announcement of the antitrust authorities, the patentholder decides whether to license the technology and discloses

\footnotetext{
${ }^{11}$ We assume that there is perfect patent protection which protects the patentholder against imitation.

${ }^{12}$ See Poddar and Sinha (2004) for an analysis of the incentives to license in a different type of product differentiation model. They consider the Hotelling's linear city model and assume that the market is covered.

${ }^{13}$ The analysis of licensing agreements between producers of complementary goods is left for future work.
} 
its licensing policy. In the third stage, the potential licensee decides whether or not to accept the licensing offer. If the antitrust authorities allow collusive licensing, the firms will always choose collusive licensing. Finally, in the fourth stage, the two firms compete in the product market by choosing prices.

While analyzing the game, subgame perfect Nash equilibrium is adopted as the solution concept. We first find the equilibrium outcomes in the product market. Then we move on to analyze the private incentives to license and show how the degree of differentiation between the products of the firms may affect their decision-making. Finally, we consider optimal licensing policy, defining social welfare as the sum of consumer surplus and producer surplus. Thus, the antitrust authorities maximize

$$
W=U\left(q_{i}, q_{j}\right)-c_{i} q_{i}-c_{j} q_{j}
$$

where $U\left(q_{i}, q_{j}\right)$ is given by (1).

\section{No Licensing}

If the firms cannot agree on a licensing arrangement, firm $i$ will produce with the new technology and firm $j$ will produce with the old technology. Their profit levels are

$$
\pi_{i}^{N}\left(p_{i}, p_{j}\right)=\left(p_{i}-c_{i}\right) q_{i} ; \quad \pi_{j}^{N}\left(p_{i}, p_{j}\right)=\left(p_{j}-c_{i}-\varepsilon\right) q_{j}
$$

where the superscript $N$ stands for the case of no licensing, and $q_{i}$ and $q_{j}$ are given by (2) above. These profit functions are concave in the relative prices. Assuming $q_{j}$ is positive, the profit-maximizing prices are

$$
\begin{aligned}
p_{i}^{N} & =\frac{\left(a(1-\theta)+c_{i}\right)(2+\theta)+\varepsilon \theta}{\left(4-\theta^{2}\right)} \\
p_{j}^{N} & =\frac{\left(a(1-\theta)+c_{i}\right)(2+\theta)+2 \varepsilon}{\left(4-\theta^{2}\right)} .
\end{aligned}
$$

Firm $j$ receives zero demand if the marginal cost it faces is so high that firm $i$ can price firm $j$ out of the market. Firm $j$ will never want to charge a price that is lower than its marginal cost of production, $c_{i}+\varepsilon$. Therefore, we can obtain the condition on $\varepsilon$ such that both of the firms are in the market in equilibrium by setting $q_{j}=0$, solving for $p_{j}$, and checking when it is higher than $c_{i}+\varepsilon$. We get that for $0 \leq \varepsilon<\widehat{\varepsilon}$, where $\widehat{\varepsilon}=\left(a-c_{i}\right)(1-\theta)(2+\theta) /\left(2-\theta^{2}\right)$, the equilibrium prices are given by (3) and (4) above. Substituting these prices in the profit 
functions, we get

$$
\begin{aligned}
\pi_{i}^{N} & =\frac{\left[\left(a-c_{i}\right)(2+\theta)(1-\theta)+\varepsilon \theta\right]^{2}}{\left(1-\theta^{2}\right)\left(4-\theta^{2}\right)^{2}} \\
\pi_{j}^{N} & =\frac{\left[\left(a-c_{i}\right)(2+\theta)(1-\theta)-\varepsilon\left(2-\theta^{2}\right)\right]^{2}}{\left(1-\theta^{2}\right)\left(4-\theta^{2}\right)^{2}}
\end{aligned}
$$

as the profit levels of the firms for small innovations.

For $\varepsilon \geq \widehat{\varepsilon}$, firm $i$ is the only seller in the market. Firm $j$ receives zero demand despite setting a price equal to marginal cost. Firm $i$ can charge the monopoly price if by doing so, it can still keep firm $j$ out of the market. Thus, for $\varepsilon \geq \widetilde{\varepsilon}$, where $\widetilde{\varepsilon}=\left(a-c_{i}\right)(2-\theta) / 2$, firm $i$ charges the monopoly price $\left(a+c_{i}\right) / 2$ and earns $\left(a-c_{i}\right)^{2} / 4$. Since the innovator can charge the monopoly price for $\varepsilon \geq \widetilde{\varepsilon}$, such innovations fall under Arrow's (1962) definition of a drastic innovation.

For $\widehat{\varepsilon} \leq \varepsilon<\widetilde{\varepsilon}$, firm $i$ is able to keep firm $j$ out of the market, but it cannot charge the monopoly price. The equilibrium prices are $p_{i}^{N}=\left[c_{i}+\varepsilon-a(1-\theta)\right] / \theta$ and $p_{j}^{N}=c_{i}+\varepsilon$. Firm $j$ makes zero while firm $i$ makes $\pi_{i}^{N}=\left(a-c_{i}-\varepsilon\right)\left(\left(c_{i}-a\right)(1-\theta)+\varepsilon\right) / \theta^{2}$.

\section{Incentives to License}

\section{i Royalty Licensing}

The existence of tacit knowledge or asymmetric information regarding the value of the licensed technology may cause the parties to prefer to have a licensing contract that specifies a royalty rate only. In this case, a flat royalty payment per unit of production, $r$, is offered as the rate at which the rival can purchase a license. If licensing occurs, the unit production cost of firm $i$ is equal to $c_{i}$ and the unit production cost of firm $j$ is equal to $c_{i}+r$. Thus, royalty licensing allows the licensor to control the marginal cost of the licensee.

We start by analyzing the Bertrand equilibria in the product market, where the firms choose prices knowing $r$. The profit functions of the firms are

$$
\pi_{i}^{R}\left(p_{i}, p_{j}, r\right)=\left(p_{i}-c_{i}\right) q_{i}+r q_{j} ; \quad \pi_{j}^{R}\left(p_{i}, p_{j}, r\right)=\left(p_{j}-c_{i}-r\right) q_{j}
$$

where the superscript $R$ stands for royalty licensing. Maximizing the profit functions with 
respect to prices and solving the first order conditions gives us the following price equilibrium:

$$
\begin{aligned}
p_{i}^{R}(r) & =\frac{\left(a(1-\theta)+c_{i}\right)(2+\theta)+3 r \theta}{\left(4-\theta^{2}\right)} \\
p_{j}^{R}(r) & =\frac{\left(a(1-\theta)+c_{i}\right)(2+\theta)+r\left(2+\theta^{2}\right)}{\left(4-\theta^{2}\right)} .
\end{aligned}
$$

In the third stage, the rival firm will not accept a licensing contract if it results in a lower profit level than its profit level before licensing. Thus, in the second stage of the game, the licensor takes this into account while deciding what royalty rate to offer to its rival. After substituting for the prices in $\pi_{i}^{R}\left(p_{i}, p_{j}, r\right)$, the licensor maximizes $\pi_{i}^{R}(r)$ with respect to $r$ subject to the constraint that $\pi_{j}^{R}(r) \geq \pi_{j}^{N}$. We get the following result.

Proposition 1 For $\varepsilon<\varepsilon^{r}<\widehat{\varepsilon}$, where $\varepsilon^{r}=\frac{\left(a-c_{i}\right)(1-\theta)(2+\theta)\left(4+2 \theta-\theta^{2}+\theta^{3}\right)}{\left(2-\theta^{2}\right)\left(8+\theta^{2}\right)}$, the optimal royalty rate is $r^{C}=\frac{\varepsilon\left(2-\theta^{2}\right)}{2\left(1-\theta^{2}\right)}$. For $\varepsilon \geq \varepsilon^{r}$, the optimal royalty rate is $r^{U}=\frac{\left(a-c_{i}\right)\left(8+\theta^{3}\right)}{2\left(8+\theta^{2}\right)}$.

The proof of Proposition 1 can be found in the Appendix. It indicates that for sufficiently small innovation sizes, firm $i$ is constrained in its determination of the royalty rate by firm $j$ 's willingness to pay. As the innovation size increases, firm $j$ loses more by not licensing. Therefore, firm $i$ can charge a higher royalty rate.

Proposition 1 implies that for sufficiently small innovation sizes, the optimal royalty rate may be larger than $\varepsilon$. The potential licensee may prefer licensing to no licensing even in cases when $r>\varepsilon$. This is because licensing with a royalty helps firms coordinate their pricing behavior. The increase in the prices more than compensates for the increase in the marginal cost of production that the licensee experiences under the licensing agreement.

Given these prices, the patentholder will license the technology with a royalty if the profit with licensing is higher than the profit without licensing. We can show that for $0 \leq \theta<1$, royalty licensing is always preferable to no licensing.

Proposition 2 Under royalty licensing, the innovator will always license the innovation.

Proposition 2 indicates first that the innovator is willing to license the innovation even to producers of close substitutes. Second, the innovator is willing to license even in cases when, under no licensing, it is the only seller in the market. Thus, allowing entry by a rival firm into the market and benefiting from its consumer base results in a higher profit than being the only supplier in the market. 
The reason behind both of these remarks is that royalty licensing allows the licensor to exert sufficient control over the cost and the price of the licensee. Under royalty licensing, the rival's unit production cost decreases by $\varepsilon$ due to its ability to use the new technology, but it increases by $r$ due to the per unit royalty it has to pay. The expressions for $p_{i}^{R}$ and $p_{j}^{R}$ above reveal that in equilibrium, firm $i$ charges a lower price than firm $j$. This means firm $i$ is able to price discriminate between its own customers and firm $j$ 's customers. This prevents firm $i$ from losing too many customers to firm $j$. Therefore, with royalty licensing, firm $i$ is able to capture at least part of the profits that firm $j$ makes as a result of the licensing arrangement, without causing the competition between them to become too intense.

\section{ii Fixed Fee Licensing}

If the firms prefer fixed fee licensing, the licensor licenses its technology with a flat lumpsum fee, $F$. The fixed fee is invariant of the quantity firm $j$ will produce using the new technology. In the price-setting stage, we know that if licensing takes place, both firms will have a production cost of $c_{i}$. The profit functions of the firms are

$$
\pi_{i}^{F}\left(p_{i}, p_{j}\right)=\left(p_{i}-c_{i}\right) q_{i}+F ; \quad \pi_{j}^{F}\left(p_{i}, p_{j}\right)=\left(p_{j}-c_{i}\right) q_{j}-F
$$

where the superscript $F$ denotes fixed fee licensing.

Maximizing these functions, we get $p_{i}^{F}=p_{j}^{F}=\left(a(1-\theta)+c_{i}\right) /(2-\theta)$. Comparing $p_{i}^{F}$ and $p_{j}^{F}$ with $p_{i}^{R}(r)$ and $p_{j}^{R}(r)$ above, we can see that as long as the royalty rate is strictly positive, the firms always end up with higher prices under royalty licensing. Thus, royalty licensing helps firms coordinate their pricing behavior.

In the third stage of the game, firm $j$ accepts the licensing deal if and only if $\pi_{j}^{F} \geq \pi_{j}^{N}$. Thus, the maximum fee that firm $i$ can charge firm $j$ is the amount that will make firm $j$ just indifferent between licensing and no licensing. Since firm $i$ 's profit level is increasing in $F$, in the first stage, firm $i$ sets

$$
F^{F}=\pi_{j}^{F}-\pi_{j}^{N}=\frac{\varepsilon\left(2-\theta^{2}\right)\left[2\left(a-c_{i}\right)(1-\theta)(2+\theta)-\varepsilon\left(2-\theta^{2}\right)\right]}{\left(1-\theta^{2}\right)\left(4-\theta^{2}\right)^{2}}
$$

for $\varepsilon<\widehat{\varepsilon}$. For $\varepsilon \geq \widehat{\varepsilon}$, firm $i$ can charge a fee such that firm $j$ is just indifferent between entering and staying out of the market.

$$
F^{F}=\pi_{j}^{F}=\frac{\left(a-c_{i}\right)^{2}(1-\theta)}{(1+\theta)(2-\theta)^{2}} .
$$


Given these fee amounts, we can analyze firm $i$ 's incentives to license under fixed fee licensing.

Proposition 3 Consider the case of fixed fee licensing. For $0 \leq \varepsilon<\widehat{\varepsilon}$, the innovator will license the innovation iff $\varepsilon \leq \varepsilon^{F N 1}\left(a, c_{i}, \theta\right)$. For $\widehat{\varepsilon} \leq \varepsilon<\widetilde{\varepsilon}$, the innovator will license the innovation iff $\varepsilon \leq \varepsilon^{F N 2}\left(a, c_{i}, \theta\right)$. For $\varepsilon \geq \widetilde{\varepsilon}$, the innovator will license the innovation iff $\theta \leq 0.61$.

The exact expressions for the critical $\varepsilon$ values, which are functions of $a, c_{i}$, and $\theta$, can be found in the Appendix. Figure 1 illustrates the results. (Figure 1 also shows the region where it is socially desirable to allow collusive licensing $(\mathrm{C})$ deals which we shall discuss below.) The solid line in Figure 1 represents the boundary between fixed fee licensing $(\mathrm{F})$ and no licensing $(\mathrm{N})$. The dotted lines outline the regions where $0 \leq \varepsilon<\varepsilon^{r}, \varepsilon^{r} \leq \varepsilon<\widehat{\varepsilon}, \widehat{\varepsilon} \leq \varepsilon<\widetilde{\varepsilon}$, and $\varepsilon \geq \widetilde{\varepsilon}$. In contrast with the case of royalty licensing, fixed fee licensing will not occur if the products are sufficiently close substitutes and the innovation is sufficiently large. When the licensor cannot use the royalty rate to discriminate between its own price and the rival's price, it does not find it profitable to license its technology if the products are close substitutes due to the increased competition it will face. Figure 1 illustrates that since $\varepsilon^{F N 1}\left(a, c_{i}, \theta\right)$ and $\varepsilon^{F N 2}\left(a, c_{i}, \theta\right)$ are decreasing functions of $\theta$, the range of innovations that are profitable to license increases as the degree of product differentiation increases. The licensor finds it optimal to license larger and larger innovations. These results imply that we should expect to see fixed fee licensing occurring between producers of sufficiently differentiated goods.

\section{iii Two-part Tariff Licensing}

Consider next the two-part tariff that includes $r$, the per-unit royalty that is paid according to the number of units that are sold, and $F$, the lump-sum payment that is paid up front when the licensing agreement is made. We assume the fixed fee cannot be negative. ${ }^{14}$ The licensing revenues of the licensor can be expressed as $r q_{j}+F$. In the final stage of the game, the profit maximization problems of the two firms are

$$
\begin{aligned}
\max _{p_{i}} \pi_{i}^{T P T}\left(p_{i}, p_{j}, r, F\right) & =\pi_{i}^{R}\left(p_{i}, p_{j}, r\right)+F=\left(p_{i}-c_{i}\right) q_{i}+r q_{j}+F \\
\max _{p_{j}} \pi_{j}^{T P T}\left(p_{i}, p_{j}, r, F\right) & =\pi_{j}^{R}\left(p_{i}, p_{j}, r\right)-F=\left(p_{j}-c_{i}-r\right) q_{j}-F
\end{aligned}
$$

\footnotetext{
${ }^{14}$ This assumption allows us to restrict the set of collusive outcomes that can be achieved by using two-part tariff licensing. As pointed out in Shapiro (1985), if negative fixed fees are allowed, the licensor can charge a large royalty rate and then compensate the licensee with a side payment.
} 


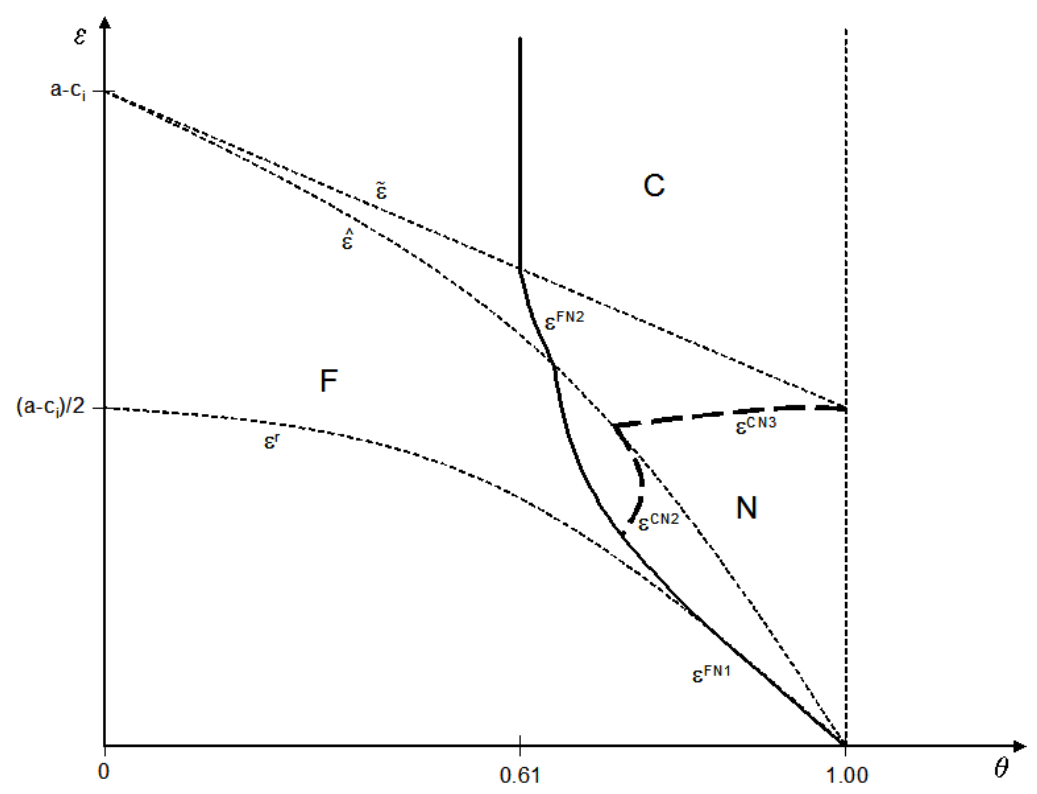

Figure 1: Incentives for Fixed Fee Licensing

where the superscript TPT stands for two-part tariff licensing. Since the firms regard the fixed fee $F$ as a constant while they are choosing prices in the last stage, solving these maximization problems with respect to the respective prices results in the same prices as in (8) and (9).

In the third stage of the game, for the licensee to accept the licensing offer of the licensor, it is necessary that the profits under licensing are not lower than the profits under no licensing. Therefore, the licensor sets the lump-sum fee, $F^{T P T}$, such that the licensee is just indifferent between licensing and not licensing given the value of $r: \pi_{j}^{T P T}(r, F)-\pi_{j}^{N}=0$. This gives us $F^{T P T}=\pi_{j}^{R}(r)-\pi_{j}^{N}$. To find the optimal per-unit royalty, the licensor solves

$$
\max _{r} \pi_{i}^{R}(r)+\pi_{j}^{R}(r)-\pi_{j}^{N} \text { such that } F \geq 0
$$

The objective function of the licensor is a concave quadratic function of $r$. Thus, solving the first-order condition gives us the following royalty rate:

$$
r^{T P T}=\frac{\left(a-c_{i}\right) \theta(2+\theta)^{2}}{2\left(4+5 \theta^{2}\right)} .
$$


For $\varepsilon<\widehat{\varepsilon}$, the lump-sum fee value that this royalty rate yields is equal to

$$
F^{T P T}=\frac{\left(a-c_{i}\right)^{2}(1-\theta)\left(2+\theta^{2}\right)^{2}}{(1+\theta)\left(4+5 \theta^{2}\right)^{2}}-\frac{\left[\left(a-c_{i}\right)(1-\theta)(2+\theta)-\varepsilon\left(2-\theta^{2}\right)\right]^{2}}{\left(1-\theta^{2}\right)\left(4-\theta^{2}\right)^{2}} .
$$

For $\varepsilon \geq \widehat{\varepsilon}$, we have $F^{T P T}=\pi_{j}^{R}(r)$ since $\pi_{j}^{N}=0$.

We need to check whether the optimal fixed fee amounts stated above are non-negative. We get the following result.

Proposition 4 For $\varepsilon<\varepsilon^{t p t}<\widehat{\varepsilon}$, where $\varepsilon^{t p t}=\frac{\left(a-c_{i}\right) \theta\left(1-\theta^{2}\right)(2+\theta)^{2}}{\left(2-\theta^{2}\right)\left(4+5 \theta^{2}\right)}$, the optimal royalty rate is ${ }_{r}^{C}=\frac{\varepsilon\left(2-\theta^{2}\right)}{2\left(1-\theta^{2}\right)}$. For $\varepsilon \geq \varepsilon^{t p t}$, the optimal royalty rate is $r^{T P T}=\frac{\left(a-c_{i}\right) \theta(2+\theta)^{2}}{2\left(4+5 \theta^{2}\right)}$.

Proposition 4 indicates that for sufficiently small innovations, i.e., for $\varepsilon<\varepsilon^{t p t}$, there will not be any two-part tariff licensing. Assuming there cannot be any side payments from the licensor to the licensee, the optimal licensing contract consists of a royalty rate only. For larger innovation sizes, the optimal licensing contract specifies both a royalty rate and a fixed fee to be paid by the licensee.

Remark 1 As $\theta \rightarrow 0, r^{T P T} \rightarrow 0$.

Looking at $r^{T P T}$, we can see that it is an increasing function of $\theta$. When the firms make a two-part tariff licensing deal, as the degree of differentiation increases (i.e., as $\theta \rightarrow 0$ ), the royalty rate gets smaller and smaller. In the limit, when $\theta=0$, the licensor charges a fixed fee only. As the competition between the firms decrease, the licensor prefers to keep the royalty charged as small as possible in order not to affect the licensing revenues collected adversely. Thus, for high levels of product differentiation, the licensor mimics the behavior of a social planner.

This equilibrium outcome gives one explanation for the low royalty rates that are observed in the real world. ${ }^{15}$ A nice empirical implication of this result is to check whether there is a direct relationship between the magnitudes of the royalty rates specified in the licensing contracts and the degree of differentiation that exists between the products of the firms signing the contract.

Finally, the following result follows directly from Proposition 2.

\footnotetext{
${ }^{15}$ Rockett (1990a) and Rostoker (1984) provide evidence for the existence of very low levels of royalties in some industries.
} 
Proposition 5 Under two-part tariff licensing, the innovator will always license the innovation.

Since royalty licensing can be viewed as a constrained version of two-part tariff licensing, it is clear that the licensor will prefer two-part tariff licensing to no licensing anytime it prefers royalty licensing to no licensing.

\section{iv Collusive Licensing}

If the antitrust authorities allow collusive licensing, the firms will always prefer collusive licensing to the other types of licensing available to them. Collusion may be achieved through various provisions in the licensing agreement. Assume that the licensing contract specifies the prices to be charged by the two parties. Since the firms will be jointly maximizing their profit levels, the prices and profits are $p_{i}^{C}=\left(a+c_{i}\right) / 2$ and $\pi_{i}^{C}=\pi_{j}^{C}=\left(a-c_{i}\right)^{2} /[4(1+\theta)]$.

\section{Optimal Licensing Policy}

Although licensing arrangements allow more firms to benefit from the superior technology of the patentholder, it is important to see how the distortions caused by the licensing deals may affect social welfare. In the following analysis, we determine the range of innovations that is socially optimal to transfer. We assume the antitrust authorities aim to maximize social welfare through the restrictions they impose on the licensing practices of firms. That is, the government can pursue a hypothetical policy through which they can tell firms when they are not allowed to pursue a specific type of licensing. However, the government cannot impose a specific licensing method that the firms should use in order to do the technology transfer. Given the guidelines provided by the government, the firms are free to choose the type of licensing method they prefer.

Specifically, the analysis of optimal licensing policy focuses on the following three questions. First, we ask whether there are regions of the parameter space where royalty, fixed fee or two-part tariff licensing is welfare-reducing. We assume the government disallows the use of a certain type of licensing if that type of licensing results in a lower welfare level than no licensing. Second, we ask whether in cases when royalty, fixed fee or two-part tariff licensing is welfare-reducing, it may be welfare-improving to allow collusive licensing. Third, we ask whether, even in cases when royalty, fixed fee or two-part tariff licensing is welfare-improving, it may be desirable to have collusive licensing instead. We assume that the government allows 
the firms to use collusive licensing if doing so results in a higher welfare level than the other types of licensing and no licensing.

We start by considering industries where the licensing agreements include a royalty rate.

\section{i Licensing with a royalty}

The following two results regarding royalty and two-part tariff licensing reveal that, if the licensing contract includes a royalty payment, the social benefit of having lower production costs may not always outweigh the social cost of having lower output choices. Lemma 2 is in line with the result in Fauli-Oller and Sandonis (2002) while Lemma 1 is an extension of their result to the case of royalty licensing.

Lemma 1 For $0 \leq \varepsilon<\varepsilon^{r}$, royalty licensing results in a higher welfare level than no licensing iff $\varepsilon \leq \varepsilon^{R N 1}\left(a, c_{i}, \theta\right)$. For $\varepsilon^{r} \leq \varepsilon<\widehat{\varepsilon}$, royalty licensing results in a higher welfare level than no licensing iff $\varepsilon^{R N 2}\left(a, c_{i}, \theta\right) \leq \varepsilon \leq \varepsilon^{R N 3}\left(a, c_{i}, \theta\right)$. For $\widehat{\varepsilon} \leq \varepsilon<\widetilde{\varepsilon}$, royalty licensing results in a higher welfare level than no licensing iff $\varepsilon \geq \varepsilon^{R N 4}\left(a, c_{i}, \theta\right)$. For $\varepsilon \geq \widetilde{\varepsilon}$, royalty licensing always results in a higher welfare level than no licensing.

Lemma 2 For $0 \leq \varepsilon<\varepsilon^{\text {tpt }}$, welfare under two-part tariff licensing is always higher than welfare under no licensing. For $\varepsilon^{\text {tpt }} \leq \varepsilon<\widehat{\varepsilon}$, two-part tariff licensing results in a higher welfare level than no licensing iff $\varepsilon^{T P T N 1}\left(a, c_{i}, \theta\right) \leq \varepsilon \leq \varepsilon^{T P T N 2}\left(a, c_{i}, \theta\right)$. For $\widehat{\varepsilon} \leq \varepsilon<\widetilde{\varepsilon}$, twopart tariff licensing results in a higher welfare level than no licensing iff $\varepsilon \geq \varepsilon^{T P T N 3}\left(a, c_{i}, \theta\right)$. For $\varepsilon \geq \widetilde{\varepsilon}$, two-part tariff licensing always results in a higher welfare level than no licensing.

Figure 2 shows the regions stated in Lemmas 1 and 2 . The solid line shows where royalty licensing $(\mathrm{R})$ will be preferred to no licensing and the long dashed line shows where two-part tariff licensing (TPT) will be preferred to no licensing. We see that if the firms do royalty or two-part tariff licensing, social welfare may be reduced in case of intermediate innovation sizes if the products of the firms are sufficiently close substitutes. ${ }^{16}$ When the innovation is sufficiently small, the royalty rate charged is also small and, hence, does not affect social welfare adversely. On the other hand, when the innovation is sufficiently large, the social benefit of having both firms use the innovation outweighs the social cost of having higher prices due to the use of royalties. Thus, in case of drastic innovations (for $\varepsilon \geq \widetilde{\varepsilon}$ ), we always have $W^{R}>W^{N}$ and $W^{T P T}>W^{N}$.

\footnotetext{
${ }^{16}$ It has been common to assume in the licensing literature that $r \leq \varepsilon$ since $r$ can be used by the firms to facilitate collusion. Our analysis indicates that this is too restrictive a policy for the antitrust authorities to make since we show that even in cases when $r>\varepsilon$, social welfare may improve as a result of licensing.
} 


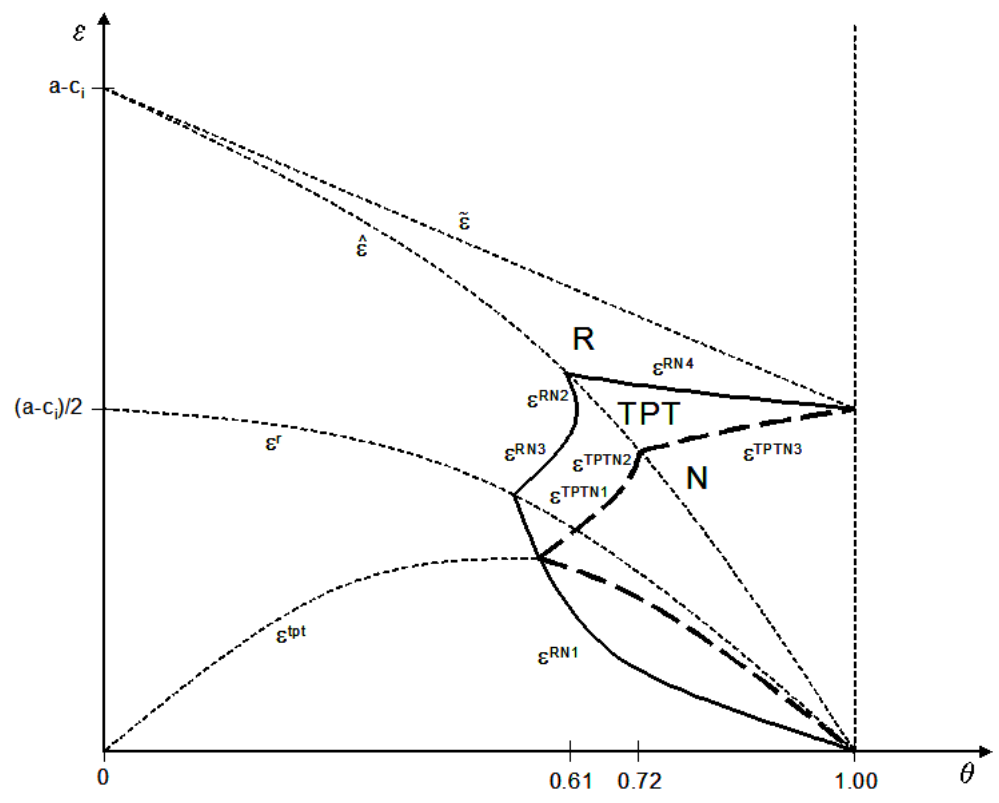

Figure 2: Welfare Implications of Licensing with a Royalty

Figure 2 also reveals that the set of parameters where two-part tariff licensing is socially preferable to no licensing is larger than the set of parameters where royalty licensing is socially preferable to no licensing. This is because when the licensing contract includes both a royalty rate and a fixed fee, the licensor finds it optimal to charge a lower royalty rate, which results in lower distortion.

We next compare welfare under royalty licensing and welfare under two-part tariff licensing with welfare under collusive licensing to see whether there are cases when collusive licensing performs better.

Lemma 3 Welfare under royalty licensing is higher than welfare under collusive licensing iff the innovation is sufficiently small, i.e., iff $\varepsilon \leq \varepsilon^{R C}<\varepsilon^{r}$.

Lemma 4 Welfare under two-part tariff licensing is always higher than welfare under collusive licensing.

While welfare under two-part tariff licensing is always higher than welfare under collusive licensing, welfare under royalty licensing is rarely higher than welfare under collusive licensing. Royalties allow the licensor to indirectly control the behavior of the licensee while under 
collusive licensing both firms have a direct control over each other's behavior. Lemmas 3 and 4 imply that allowing the firms to have such a direct control over each other's behavior may be desirable in case of royalty licensing only. This is because the distortion caused by the royalty rate charged under royalty licensing is higher. The desirability of collusive licensing depends on how large the innovation is. Lemma 3 indicates that since $\varepsilon^{R C}<\varepsilon^{r}<\widehat{\varepsilon}$, it may be desirable to allow the firms to use collusive licensing instead of royalty licensing not only in regions where there is only one firm in the market, but also in regions where both firms are in the market.

Although it may be optimal to have collusive licensing instead of royalty licensing in many cases, we still need to check when it is optimal to have collusive licensing instead of no licensing in order to determine optimal licensing policy.

Lemma 5 For $0 \leq \varepsilon<\widehat{\varepsilon}$, collusive licensing results in a higher welfare level than no licensing iff $\varepsilon^{C N 1}\left(a, c_{i}, \theta\right) \leq \varepsilon \leq \varepsilon^{C N 2}\left(a, c_{i}, \theta\right)$. For $\widehat{\varepsilon} \leq \varepsilon<\widetilde{\varepsilon}$, collusive licensing results in a higher welfare level than no licensing iff $\varepsilon \geq \varepsilon^{C N 3}\left(a, c_{i}, \theta\right)$. For $\varepsilon \geq \widetilde{\varepsilon}$, collusive licensing always results in a higher welfare level than no licensing.

The graphical representation of the critical $\varepsilon$ values stated in Lemma 5 looks similar to the graph for Lemma 2. For $\varepsilon<\widetilde{\varepsilon}$, allowing collusion in the licensing stage may harm social welfare if and only if the products are close substitutes and the innovation size is sufficiently small. Allowing firms to collude and produce at a lower cost in cases when the firms are not competing intensely does not hurt social welfare. For $\varepsilon \geq \widetilde{\varepsilon}$, having collusive licensing is always preferable to having no licensing at all. If the innovation is a drastic one or close to a drastic one, it is better to have two firms and high prices than to have one firm and high prices due to the larger output we would have with two firms operating in the market.

We can finally combine our results to state what the optimal licensing policy is. Note that the government always finds it optimal to allow technology transfers where the licensee pays a fixed fee to the licensor.

Lemma 6 Welfare under fixed fee licensing is always higher than welfare under no licensing and welfare under collusive licensing.

Since fixed fee licensing achieves the diffusion of the innovator's superior technology without causing any distortions in the output choice of the licensee, total industry output always 


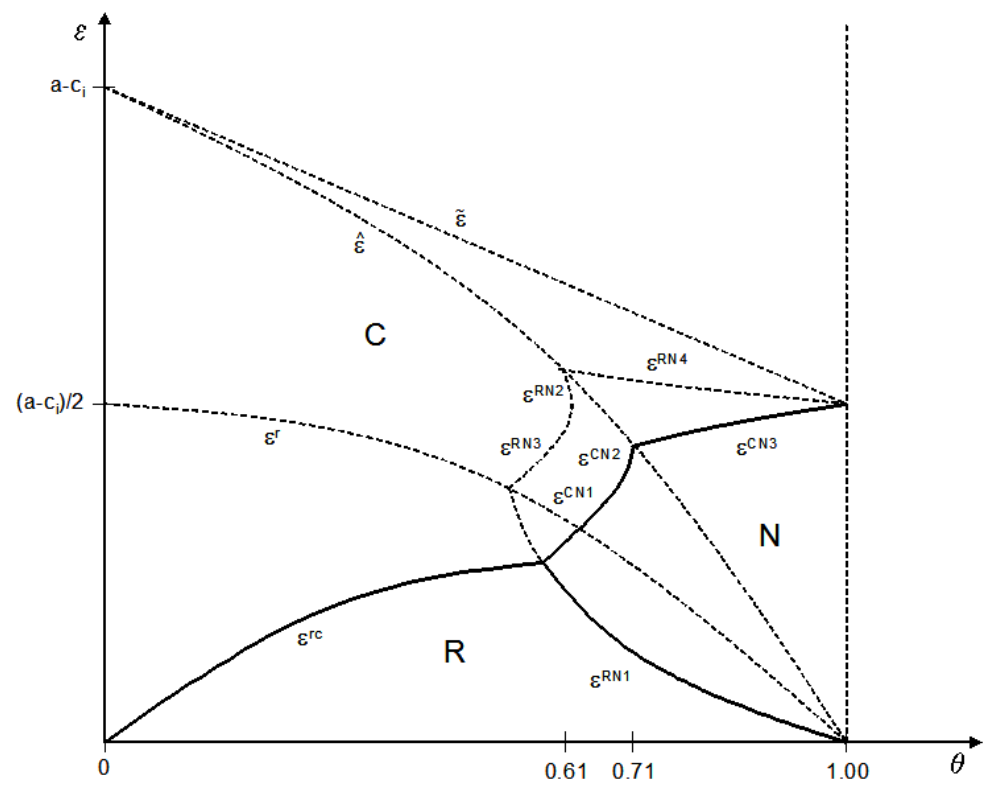

Figure 3: Policy under Royalty Licensing

increases. Thus, even if the government finds it optimal to restrict royalty, two-part tariff or collusive licensing, it will always allow fixed fee licensing.

We first consider industries where, due to the existence of tacit knowledge and asymmetric information, the firms prefer to do royalty licensing only. Proposition 6 states what the optimal licensing policy is.

Proposition 6 If royalty licensing is the preferred method of licensing by the firms, it is socially optimal to have royalty licensing only in cases when the innovation size is very small. For intermediate innovation sizes and low degrees of differentiation, it is optimal to allow the firms to do fixed fee licensing only. For sufficiently large innovations and high degrees of differentiation, it is socially optimal to allow collusive licensing.

Figure 3 illustrates the types of technology transfer deals that will take place under the optimal licensing policy stated in Proposition 6. In case of royalty licensing, it is optimal to allow collusive licensing for a large portion of the parameter space as long as the innovation is sufficiently large and the products are sufficiently differentiated. Whenever the government allows collusive licensing deals, the firms will prefer it over the other methods of technology transfer since it yields the highest profits. Figure 3 furthermore illustrates that some licens- 


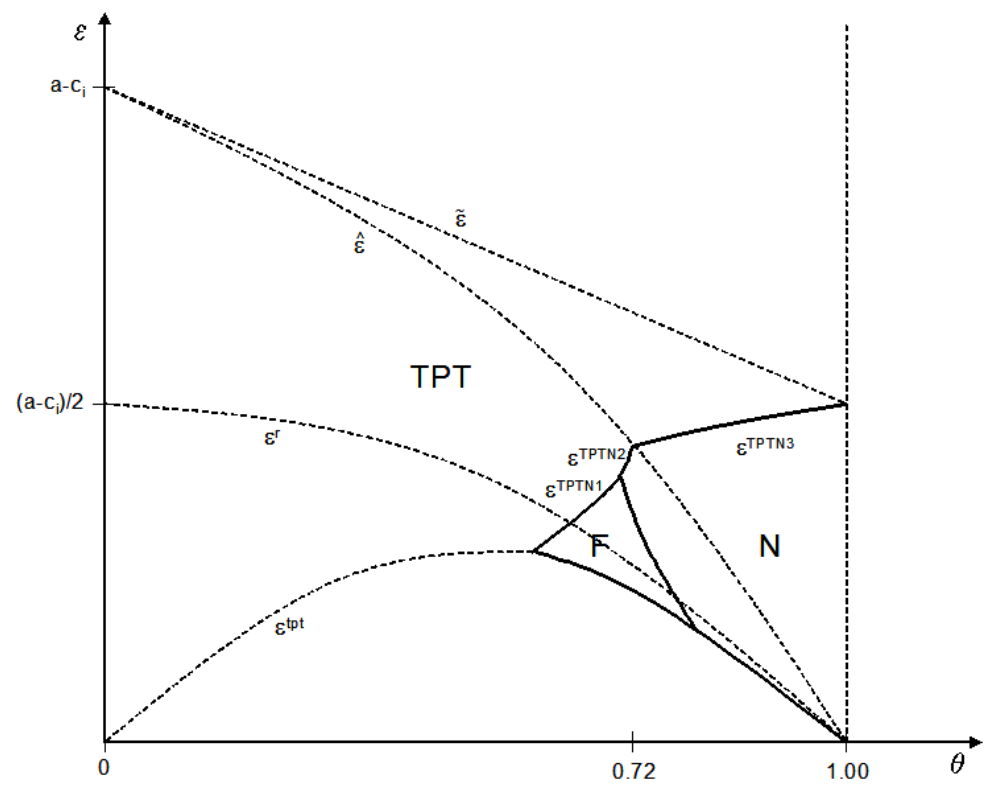

Figure 4: Policy under Two-part Tariff Licensing

ing deals that are welfare improving under collusive licensing will not be socially desirable under royalty licensing. That is, for $\varepsilon>\varepsilon^{R N 1}\left(a, c_{i}, \theta\right)$, the region where royalty licensing is welfare reducing (which falls to the right of $\varepsilon^{R N 1}\left(a, c_{i}, \theta\right), \varepsilon^{R N 2}\left(a, c_{i}, \theta\right), \varepsilon^{R N 3}\left(a, c_{i}, \theta\right)$ and $\left.\varepsilon^{R N 4}\left(a, c_{i}, \theta\right)\right)$ is larger than the region where collusive licensing is welfare reducing (which falls to the right of $\varepsilon^{C N 1}\left(a, c_{i}, \theta\right), \varepsilon^{C N 2}\left(a, c_{i}, \theta\right)$, and $\left.\varepsilon^{C N 3}\left(a, c_{i}, \theta\right)\right)$. This is because the distortion caused by royalty licensing is larger than the distortion caused by collusive licensing. Thus, under collusive licensing it is desirable to restrict the transfer of a smaller set of innovations.

Proposition 6 also states that in cases where the products are close substitutes, if the innovation size is relatively small, it is optimal to allow the firms to do fixed fee licensing only. However, since the firms do not have any incentives to do fixed fee licensing, there will not be any technology transfers in this region.

Next, consider the case of two-part tariff licensing.

Proposition 7 If the firms prefer to make a two-part tariff licensing agreement, collusive agreements should never be allowed. In case of intermediate innovations and close substitutes, it is socially optimal to have fixed fee licensing only. 
We know from Lemma 2 that two-part tariff licensing is welfare reducing when the innovation size is sufficiently small and the products are relatively close substitutes. In such cases, it is socially desirable to allow the firms to do fixed fee licensing only since welfare under fixed fee licensing is always higher than welfare under no licensing. As shown in Figure 4, the firms will do fixed fee licensing in this region if the products are sufficiently differentiated.

We next consider optimal licensing policy in industries with low imitation or high monitoring costs, where the firms choose to do fixed fee licensing only.

\section{ii Licensing without a royalty}

Fixed fee licensing is always socially preferable to no licensing or collusive licensing. However, we know from Proposition 3 that the firms do not have incentives to make fixed fee licensing deals for low levels of product differentiation and sufficiently large innovations. In such cases, it may be socially desirable to allow collusive licensing deals if doing so results in a higher welfare level than having no technology transfers. The following proposition defines the optimal licensing policy.

Proposition 8 If fixed fee licensing is the preferred method of licensing by the firms, it is socially optimal to allow collusive licensing for sufficiently high innovation sizes and low degrees of differentiation.

Figure 1 illustrates the optimal outcome for society under fixed fee licensing, taking into account the private incentives of firms. The long dashed line in Figure 1 indicates that in cases when the firms do not have incentives to do fixed fee licensing, allowing collusive licensing may increase social welfare if the innovation size is sufficiently large. That is, collusive licensing should be tolerated mainly in cases where the degree of product differentiation is sufficiently low and the non-innovating firm would not be able to enter the market without collusive licensing. This is because in such cases it is better to have two firms charging high prices than one firm charging a high price in the market.

The results on optimal licensing policy can be summarized in the following way. For sufficiently small innovations and low degrees of product differentiation, it is socially optimal to have fixed fee licensing only. In this region, the firms do not find it privately profitable to have fixed fee licensing deals if the innovation is sufficiently large and the products are sufficiently close substitutes. Thus, we can see in Figures 1, 3 and 4 that under optimal licensing policy, if the degree of product differentiation is sufficiently low, innovations that 
are sufficiently small will not be licensed. Figures 1, 3 and 4 also indicate that the government should have the least restrictive licensing policy in industries where firms use two-part tariff licensing. That is, the set of innovations that are socially optimal to transfer is the largest under two-part tariff licensing. In all of the figures, the range of innovation sizes that is socially optimal to transfer decreases as the degree of product differentiation decreases. In the limit, as the degree of product differentiation converges to zero, it is socially desirable to transfer drastic innovations only. In industries where the firms prefer to do fixed fee or royalty licensing only, it may be socially desirable to encourage such transfers by allowing collusive licensing deals.

\section{Conclusion}

The antitrust implications of licensing arrangements have been the subject of policy debates in different countries including the United States and Australia. We have analyzed optimal licensing policy in industries where imitation is highly probable and firms prefer to have fixed-fee licensing only, in industries where technology transfer deals are characterized by asymmetric information and firms prefer to have royalty licensing only, and in industries where the firms do two-part tariff licensing. We have explored when firms should be allowed to include royalties and when they should be allowed to fix prices in the licensing contracts.

Our results imply that licensing policy geared towards industries where products tend to be more homogeneous should be different from licensing policy geared towards industries where products tend to be more differentiated. Moreover, the antitrust authorities should treat technology transfer deals that take place between actual competitors differently from technology transfer deals that take place between potential competitors.

Specifically, the results show that it is too restrictive a policy guideline to regard all collusive licensing deals as anticompetitive since collusive licensing may result in a higher welfare level than royalty licensing and no licensing. The results imply that the antitrust authorities need to be less concerned about collusive licensing deals that take place between potential (as opposed to actual) competitors. In fact, we find that if the innovation is drastic, it is always socially desirable to encourage its transfer. On the other hand, if the innovation size is sufficiently small and the degree of product differentiation is sufficiently low, it is not socially desirable to have any technology transfers. Thus, the antitrust authorities should have the most restrictive licensing policy in case of technology transfers that take place between actual competitors in industries where products tend to be more homogeneous. 
This is because licensing deals between producers of close substitutes that involve sufficiently small (nondrastic) innovations are socially desirable if and only if the firms use fixed fee licensing. However, the firms do not find it optimal to use fixed fee licensing for sufficiently high innovation sizes and low degrees of differentiation. In the limit, as the degree of product differentiation converges to zero, it is socially desirable to transfer drastic innovations only. The range of innovation sizes that is socially optimal to transfer increases as the degree of product differentiation increases.

There are a number of ways in which the paper can be extended. First, the policy implications of licensing arrangements between producers of complementary goods can be analyzed. Second, optimal licensing policy can be analyzed by considering the effects of licensing on pre-licensing or post-licensing $\mathrm{R} \& \mathrm{D}$ incentives. Third, the assumptions made regarding the market structure can be relaxed by allowing for a higher number of firms or entry. The effects of having multiple potential licensors or multiple potential licensees on the licensing behavior of firms can be analyzed. Finally, since licensing contracts sometimes include non-linear royalties, the impact of non-linear royalties on optimal licensing policy can be explored. 


\section{Appendix}

\section{A Proof of Proposition 1}

In case of royalty licensing, the licensor maximizes $\pi_{i}^{R}(r)$ with respect to $r$ subject to the constraint that $\pi_{j}^{R}(r)-\pi_{j}^{N} \geq 0$. The unconstrained maximization of $\pi_{i}^{R}(r)$ gives us the following solution:

$$
r^{U}=\frac{\left(a-c_{i}\right)\left(8+\theta^{3}\right)}{2\left(8+\theta^{2}\right)}
$$

The licensor will choose $r^{U}$ if it satisfies the incentive compatibility constraint of the licensee.

It is straightforward to check that the incentive compatibility constraint of the licensee is satisfied for $\varepsilon \geq \widehat{\varepsilon}$. For $\varepsilon<\widehat{\varepsilon}$, plugging $r^{U}$ into the expression for $\pi_{j}^{R}(r)-\pi_{j}^{N}$ yields:

$$
\begin{aligned}
\pi_{j}^{R}(r)-\pi_{j}^{N}= & {\left[\left(a-c_{i}\right)(1-\theta)\left(4-\theta^{2}\right)\left(2+\theta^{2}\right)\right]^{2} } \\
& -\left(8+\theta^{2}\right)^{2}\left[\left(a-c_{i}\right)(1-\theta)(2+\theta)-\varepsilon\left(2-\theta^{2}\right)\right]^{2} .
\end{aligned}
$$

This expression, which is in the form of $a^{2}-b^{2}$, can be factored into $(a+b)(a-b)$. Note that since we are interested in $\varepsilon<\widehat{\varepsilon}=\frac{\left(a-c_{i}\right)(1-\theta)(2+\theta)}{\left(2-\theta^{2}\right)}, b>0$. Therefore, the sign of $\pi_{j}^{R}(r)-\pi_{j}^{N}$ is the same as the sign of $(a-b)$. Solving $(a-b)=0$ for $\varepsilon$ gives us:

$$
\varepsilon^{r}=\frac{\left(a-c_{i}\right)(1-\theta)(2+\theta)\left(4+2 \theta-\theta^{2}+\theta^{3}\right)}{\left(8+\theta^{2}\right)\left(2-\theta^{2}\right)}
$$

Since $(a-b)$ is an increasing function of $\varepsilon$, we know that $\pi_{j}^{R}(r)-\pi_{j}^{N} \geq 0$ for all $\varepsilon \geq \varepsilon^{r}$. Comparing $\widehat{\varepsilon}$ with $\varepsilon^{r}$, we can easily show that $\varepsilon^{r}<\widehat{\varepsilon}$ for $0 \leq \theta<1$. Therefore, the licensor cannot charge $r^{U}$ for $\varepsilon<\varepsilon^{r}<\widehat{\varepsilon}$.

There are two values of $r$ that satisfy $\pi_{j}^{R}(r)-\pi_{j}^{N}=0$. They are:

$$
{ }_{r}^{C 1}=\frac{2\left(a-c_{i}\right)(1-\theta)(2+\theta)-\varepsilon\left(2-\theta^{2}\right)}{2\left(1-\theta^{2}\right)} ; \quad r^{C 2}=\frac{\varepsilon\left(2-\theta^{2}\right)}{2\left(1-\theta^{2}\right)} .
$$

The licensor will choose the one that yields a higher profit level. Evaluating $\pi_{i}^{R}(r)$ at $r^{C 1}$ and $r^{C 2}$ yields that $\pi_{i}^{R}\left(r=r^{C 2}\right)>\pi_{i}^{R}\left(r=r^{C 1}\right)$ for $\varepsilon<\widehat{\varepsilon}$. 


\section{B Proof of Proposition 2}

For $0 \leq \varepsilon<\varepsilon^{r}$, the relevant royalty rate is $r^{C 2}=\frac{\varepsilon\left(2-\theta^{2}\right)}{2\left(1-\theta^{2}\right)}$. Plugging $r^{C 2}$ into $\pi_{j}^{R}(r)$ and comparing $\pi_{i}^{R}$ with $\pi_{i}^{N}$ gives us:

$$
\pi_{i}^{R}-\pi_{i}^{N}=\frac{\varepsilon\left[\left(a-c_{i}\right)\left(8-4 \theta-8 \theta^{2}+6 \theta^{3}-2 \theta^{5}\right)-\varepsilon\left(8-4 \theta^{2}-\theta^{4}\right)\right]}{4\left(1-\theta^{2}\right)^{2}\left(4-\theta^{2}\right)}
$$

which is a concave quadratic function of $\varepsilon$. Setting $\pi_{i}^{R}-\pi_{i}^{N}=0$, we get $\varepsilon_{1}=0$ and $\varepsilon_{2}=\frac{2\left(a-c_{i}\right)\left(1-\theta^{2}\right)(2+\theta)\left(2-2 \theta+\theta^{2}\right)}{\left(8-4 \theta^{2}-\theta^{4}\right)}$. Since $\varepsilon^{r}<\varepsilon_{2}$ for $0 \leq \theta<1$, we have $\pi_{i}^{R} \geq \pi_{i}^{N}$ for $0 \leq \varepsilon<\varepsilon^{r}$.

For $\varepsilon^{r} \leq \varepsilon<\widehat{\varepsilon}$, the relevant royalty rate is $r^{U}=\frac{\left(a-c_{i}\right)\left(8+\theta^{3}\right)}{2\left(8+\theta^{2}\right)}$. Plugging $r^{U}$ into $\pi_{i}^{R}(r)$ and comparing gives us:

$$
\pi_{i}^{R}-\pi_{i}^{N}=\frac{\left(a-c_{i}\right)^{2}(2+\theta)\left(6-\theta+\theta^{2}\right)}{4(1+\theta)\left(8+\theta^{2}\right)}-\frac{\left[\left(a-c_{i}\right)(1-\theta)(2+\theta)+\varepsilon \theta\right]^{2}}{\left(1-\theta^{2}\right)\left(4-\theta^{2}\right)^{2}}
$$

To show that $\pi_{i}^{R}-\pi_{i}^{N} \geq 0$, consider the derivative with respect to $\varepsilon$. We get $\frac{\partial\left(\pi_{i}^{R}-\pi_{i}^{N}\right)}{\partial \varepsilon}=$ $\frac{-2 \theta\left(\left(a-c_{i}\right)(1-\theta)(2+\theta)+\varepsilon \theta\right)}{\left(1-\theta^{2}\right)\left(4-\theta^{2}\right)^{2}}<0$. Therefore, if $\pi_{i}^{R}-\pi_{i}^{N} \geq 0$ for the largest value of $\varepsilon$ we are interested in, it is nonnegative everywhere. Plugging in $\widehat{\varepsilon}$ for $\varepsilon$ and checking the sign of $\pi_{i}^{R}-\pi_{i}^{N}$ for $0 \leq \theta<1$ gives us the result.

For $\widehat{\varepsilon} \leq \varepsilon<\widetilde{\varepsilon}$, we have:

$$
\pi_{i}^{R}-\pi_{i}^{N}=\frac{\left(a-c_{i}\right)^{2}(2+\theta)\left(6-\theta+\theta^{2}\right)}{4(1+\theta)\left(8+\theta^{2}\right)}-\frac{\left(a-c_{i}-\varepsilon\right)\left[\left(a-c_{i}\right)(1-\theta)-\varepsilon\right]}{\theta^{2}}
$$

Again, to show that $\pi_{i}^{R}-\pi_{i}^{N} \geq 0$, consider the derivative with respect to $\varepsilon$. We get $\frac{\partial\left(\pi_{i}^{R}-\pi_{i}^{N}\right)}{\partial \varepsilon}=$ $-\frac{\left(a-c_{i}\right)(2-\theta)-2 \varepsilon}{\theta^{2}}$ which is negative because we are considering $\varepsilon<\widetilde{\varepsilon}=\frac{\left(a-c_{i}\right)(2-\theta)}{2}$. Therefore, if $\pi_{i}^{R}-\pi_{i}^{N} \geq 0$ for the largest value of $\varepsilon$ we are interested in, it is nonnegative everywhere. Plugging in $\widetilde{\varepsilon}$ for $\varepsilon$ and checking the sign of $\pi_{i}^{R}-\pi_{i}^{N}$ for $0 \leq \theta<1$ gives us the result.

For $\varepsilon \geq \widetilde{\varepsilon}$, we have:

$$
\pi_{i}^{R}-\pi_{i}^{N}=\frac{\left(a-c_{i}\right)^{2}(1-\theta)}{(1+\theta)\left(8+\theta^{2}\right)}
$$

which is positive for $0 \leq \theta<1$. 


\section{Proof of Proposition 3}

For $0 \leq \varepsilon<\widehat{\varepsilon}$, the licensor prefers fixed fee licensing to no licensing whenever the following expression is nonnegative:

$$
\pi_{i}^{F}-\pi_{i}^{N}=\frac{\varepsilon\left[2\left(a-c_{i}\right)(1-\theta)^{2}(2+\theta)^{2}-\varepsilon\left(4-3 \theta^{2}+\theta^{4}\right)\right]}{\left(1-\theta^{2}\right)\left(4-\theta^{2}\right)^{2}}
$$

$\pi_{i}^{F}-\pi_{i}^{N}$ is a concave quadratic function of $\varepsilon$ and its roots are given by $\varepsilon_{1}=0$ and $\varepsilon_{2}=$ $\frac{2\left(a-c_{i}\right)(1-\theta)^{2}(2+\theta)^{2}}{\left(4-3 \theta^{2}+\theta^{4}\right)}$. Since $\varepsilon_{2}=\varepsilon^{F N 1}<\widehat{\varepsilon}$ for high values of $\theta$, firm $i$ will prefer fixed fee licensing as long as $\varepsilon \leq \min \left\{\varepsilon^{F N 1}, \widehat{\varepsilon}\right\}$.

For $\widehat{\varepsilon} \leq \varepsilon<\widetilde{\varepsilon}$, the licensor prefers fixed fee licensing to no licensing whenever the following expression is nonnegative:

$$
\pi_{i}^{F}-\pi_{i}^{N}=\frac{2\left(a-c_{i}\right)^{2}(1-\theta)}{(1+\theta)(2-\theta)^{2}}+\frac{\left(a-c_{i}-\varepsilon\right)\left[\left(a-c_{i}\right)(1-\theta)-\varepsilon\right]}{\theta^{2}}
$$

Note that $\pi_{i}^{F}-\pi_{i}^{N}$ is a convex quadratic function of $\varepsilon$. It has two roots, $\varepsilon_{1}$ and $\varepsilon_{2}$. Firm $i$ will prefer fixed fee licensing for $\varepsilon \leq \varepsilon_{1}=\frac{\left(a-c_{i}\right)\left[4-3 \theta^{2}+\theta^{3}-\theta \sqrt{(1+\theta)\left(-4+8 \theta-3 \theta^{2}+\theta^{3}\right)}\right]}{2(1+\theta)(2-\theta)}$ and $\varepsilon \geq$ $\varepsilon_{2}=\frac{\left(a-c_{i}\right)\left[4-3 \theta^{2}+\theta^{3}+\theta \sqrt{(1+\theta)\left(-4+8 \theta-3 \theta^{2}+\theta^{3}\right)}\right]}{2(1+\theta)(2-\theta)}$. However, since we are interested in $\widehat{\varepsilon} \leq \varepsilon<\widetilde{\varepsilon}$, we need to make sure that both of the roots fall within that region. Graphing $\widehat{\varepsilon}, \widetilde{\varepsilon}, \varepsilon_{1}$, and $\varepsilon_{2}$ against $\theta$ shows that $\widetilde{\varepsilon}<\varepsilon_{2}$ for $0 \leq \theta<1$. Therefore, firm $i$ will prefer fixed fee licensing as long as $\varepsilon \leq \varepsilon^{F N 2}=\varepsilon_{1}$.

For $\varepsilon \geq \widetilde{\varepsilon}$, the licensor prefers fixed fee licensing to no licensing whenever the following expression is nonnegative:

$$
\pi_{i}^{F}-\pi_{i}^{N}=\left(a-c_{i}\right)^{2}\left[\frac{\left(4-8 \theta+3 \theta^{2}-\theta^{3}\right)}{4(1+\theta)(2-\theta)^{2}}\right]
$$

Numerical estimation shows that $\pi_{i}^{F}-\pi_{i}^{N} \geq 0$ for $\theta \leq 0.61$.

\section{Proof of Proposition 4}

The licensor will set

$$
r^{T P T}=\frac{\left(a-c_{i}\right) \theta(2+\theta)^{2}}{2\left(4+5 \theta^{2}\right)}
$$


as long as doing so gives $F \geq 0$. For $\varepsilon \geq \widehat{\varepsilon}, F=\pi_{j}^{R}(r)>0$. For $\varepsilon<\widehat{\varepsilon}$, plugging $r^{T P T}$ into the expression for $\pi_{j}^{R}(r)-\pi_{j}^{N}$ and solving for the critical $\varepsilon$ value as we did in the proof of Proposition 1 gives us

$$
\varepsilon^{t p t}=\frac{\left(a-c_{i}\right) \theta\left(1-\theta^{2}\right)(2+\theta)^{2}}{\left(2-\theta^{2}\right)\left(4+5 \theta^{2}\right)} .
$$

Thus, $F=\pi_{j}^{R}(r)-\pi_{j}^{N} \geq 0$ for all $\varepsilon \geq \varepsilon^{t p t}$. Comparing $\varepsilon^{t p t}$ with $\varepsilon^{r}$, we can easily show that $\varepsilon^{t p t}<\varepsilon^{r}$ for $0 \leq \theta<1$.

For $\varepsilon<\varepsilon^{t p t}$, the licensor will set the royalty rate such that $\pi_{j}^{R}(r)-\pi_{j}^{N}=0$. This royalty rate is given by $r^{C 2}=\frac{\varepsilon\left(2-\theta^{2}\right)}{2\left(1-\theta^{2}\right)}$ as we showed in the proof of Proposition 1 .

\section{E Proof of Proposition 5}

The result follows from Proposition 2. Since $\pi_{i}^{T P T} \geq \pi_{i}^{R}$, firm $i$ should prefer two-part tariff licensing to no licensing whenever it prefers royalty licensing to no licensing.

\section{F Proof of Lemma 1}

For $0 \leq \varepsilon<\varepsilon^{r}$, we have:

$$
W^{R}-W^{N}=\frac{\varepsilon\left[4\left(a-c_{i}\right)(1-\theta)^{2}(1+\theta)-\varepsilon\left(4-3 \theta^{2}\right)\right]}{8\left(1-\theta^{2}\right)^{2}} .
$$

$W^{R}-W^{N}$ is a concave quadratic function of $\varepsilon$ and its roots are given by $\varepsilon_{1}=0$ and $\varepsilon_{2}=\frac{4\left(a-c_{i}\right)(1-\theta)^{2}(1+\theta)}{\left(4-3 \theta^{2}\right)}$. Since $\varepsilon_{2}=\varepsilon^{R N 1}<\varepsilon^{r}$ for some $\theta$ values, royalty licensing results in a higher welfare level than no licensing as long as $\varepsilon \leq \min \left\{\varepsilon^{R N 1}, \varepsilon^{r}\right\}$.

For $\varepsilon^{r} \leq \varepsilon<\widehat{\varepsilon}$,

$$
\begin{aligned}
W^{R}-W^{N}= & \frac{\left(a-c_{i}\right)^{2}\left(304+48 \theta+108 \theta^{2}+16 \theta^{3}+11 \theta^{4}-\theta^{5}\right)}{8(1+\theta)\left(8+\theta^{2}\right)^{2}} \\
& -\frac{2\left(a-c_{i}\right)^{2} B-2\left(a-c_{i}\right) \varepsilon B+\varepsilon^{2}\left(12-9 \theta^{2}+2 \theta^{4}\right)}{2\left(1-\theta^{2}\right)\left(4-\theta^{2}\right)^{2}}
\end{aligned}
$$

where $B=(1-\theta)(2+\theta)^{2}(3-2 \theta)$. This is a concave quadratic function of $\varepsilon$. Setting $W^{R}-W^{N}=0$, we get $\varepsilon=\frac{\left(a-c_{i}\right)(2+\theta)\left[2(1-\theta)(2+\theta)(3-2 \theta)\left(8+\theta^{2}\right) \pm(2-\theta) \sqrt{(-1+\theta) C}\right]}{2\left(8+\theta^{2}\right)\left(12-9 \theta^{2}+2 \theta^{4}\right)}$, where $C=$ $-1344+1728 \theta+992 \theta^{2}-208 \theta^{3}+12 \theta^{4}-160 \theta^{5}-133 \theta^{6}-57 \theta^{7}-22 \theta^{8}+2 \theta^{9}$. Let $\varepsilon^{R N 2}$ and $\varepsilon^{R N 3}$ represent the two roots. Graphical comparison of the various $\varepsilon$ values reveals that 
royalty licensing results in a higher welfare level than no licensing for $\max \left\{\varepsilon^{R N 2}, \varepsilon^{r}\right\} \leq \varepsilon \leq$ $\min \left\{\varepsilon^{R N 3}, \widehat{\varepsilon}\right\}$.

For $\widehat{\varepsilon} \leq \varepsilon<\widetilde{\varepsilon}$, we have:

$$
\begin{aligned}
W^{R}-W^{N}= & \frac{\left(a-c_{i}\right)^{2}\left(304+48 \theta+108 \theta^{2}+16 \theta^{3}+11 \theta^{4}-\theta^{5}\right)}{8(1+\theta)\left(8+\theta^{2}\right)^{2}} \\
& +\frac{\left(a-c_{i}-\varepsilon\right)\left[\left(a-c_{i}\right)(1-2 \theta)-\varepsilon\right]}{2 \theta^{2}}
\end{aligned}
$$

This is a convex quadratic function of $\varepsilon$. Setting $W^{R}-W^{N}=0$ and solving for $\varepsilon$ gives us $\varepsilon=$ $\frac{\left(a-c_{i}\right)\left[16-14 \theta^{2}-2 \theta^{4} \pm \sqrt{(1+\theta)\left(-48+208 \theta-44 \theta^{2}+48 \theta^{3}-7 \theta^{4}+5 \theta^{5}\right)}\right]}{2(1+\theta)\left(8+\theta^{2}\right)}$. Let $\varepsilon_{1}$ and $\varepsilon_{2}$ stand for the two roots.

Graphical analysis reveals that $\widehat{\varepsilon}>\varepsilon_{1}=\frac{\left(a-c_{i}\right)\left[16-14 \theta^{2}-2 \theta^{4}-\sqrt{(1+\theta)\left(-48+208 \theta-44 \theta^{2}+48 \theta^{3}-7 \theta^{4}+5 \theta^{5}\right)}\right]}{2(1+\theta)\left(8+\theta^{2}\right)}$. Therefore, collusive licensing results in a higher welfare level than no licensing for $\varepsilon \geq \varepsilon^{R N 4}=$ $\varepsilon_{2}$.

For $\varepsilon \geq \widetilde{\varepsilon}$, we have:

$$
W^{R}-W^{N}=\frac{\left(a-c_{i}\right)^{2}(1-\theta)\left(28-8 \theta+7 \theta^{2}-\theta^{3}+\theta^{4}\right)}{2(1+\theta)\left(8+\theta^{2}\right)^{2}}
$$

which is positive for $\theta \in[0,1)$.

\section{G Proof of Lemma 2}

For $0 \leq \varepsilon<\varepsilon^{t p t}$,

$$
W^{T P T}-W^{N}=\frac{\varepsilon\left[4\left(a-c_{i}\right)(1-\theta)^{2}(1+\theta)-\varepsilon\left(4-3 \theta^{2}\right)\right]}{8\left(1-\theta^{2}\right)^{2}} .
$$

$W^{T P T}-W^{N}$ is a concave quadratic function of $\varepsilon$ and its roots are given by $\varepsilon_{1}=0$ and $\varepsilon_{2}=\frac{4\left(a-c_{i}\right)(1-\theta)^{2}(1+\theta)}{\left(4-3 \theta^{2}\right)}$. Since $\varepsilon^{t p t}<\varepsilon_{2}$ for all $\theta$ values, two-part tariff licensing always results in a higher welfare level than no licensing.

For $\varepsilon^{t p t} \leq \varepsilon<\widehat{\varepsilon}$,

$$
\begin{aligned}
W^{T P T}-W^{N}= & \frac{\left(a-c_{i}\right)^{2}\left(24+4 \theta+23 \theta^{2}+3 \theta^{3}\right)}{8(1+\theta)\left(4+5 \theta^{2}\right)} \\
& -\frac{2\left(a-c_{i}\right)^{2} B-2\left(a-c_{i}\right) \varepsilon B+\varepsilon^{2}\left(12-9 \theta^{2}+2 \theta^{4}\right)}{2\left(1-\theta^{2}\right)\left(4-\theta^{2}\right)^{2}}
\end{aligned}
$$


where $B=(1-\theta)(2+\theta)^{2}(3-2 \theta)$. This is a concave quadratic function of $\varepsilon$. Its roots are $\varepsilon=\frac{\left(a-c_{i}\right)(2+\theta)^{2}\left[2(1-\theta)(3-2 \theta)\left(4+5 \theta^{2}\right) \pm(2-\theta) \sqrt{(1-\theta)\left(4+5 \theta^{2}\right)\left(36-60 \theta+37 \theta^{2}-51 \theta^{3}+22 \theta^{4}+6 \theta^{5}\right)}\right]}{96+48 \theta^{2}-74 \theta^{4}+20 \theta^{6}}$. Let $\varepsilon^{T P T N 1}$ and $\varepsilon^{T P T N 2}$ represent the two roots. Graphical analysis reveals that two-part tariff licensing results in a higher welfare level than no licensing for $\varepsilon^{T P T N 1} \leq \varepsilon \leq \min \left\{\varepsilon^{T P T N 2}, \widehat{\varepsilon}\right\}$.

For $\widehat{\varepsilon} \leq \varepsilon<\widetilde{\varepsilon}$, we have:

$$
W^{T P T}-W^{N}=\frac{\left(a-c_{i}\right)^{2}\left(24+4 \theta+23 \theta^{2}+3 \theta^{3}\right)}{8(1+\theta)\left(4+5 \theta^{2}\right)}+\frac{\left(a-c_{i}-\varepsilon\right)\left[\left(a-c_{i}\right)(1-2 \theta)-\varepsilon\right]}{2 \theta^{2}}
$$

This expression is a convex quadratic function of $\varepsilon$. Setting $W^{T P T}-W^{N}=0$, we get $\varepsilon=\frac{\left(a-c_{i}\right)\left[8+2 \theta^{2}-10 \theta^{4} \pm \sqrt{(1+\theta)\left(4+5 \theta^{2}\right)\left(-8+12 \theta-3 \theta^{2}+17 \theta^{3}\right)}\right]}{2(1+\theta)\left(4+5 \theta^{2}\right)}$. Let $\varepsilon_{1}$ and $\varepsilon_{2}$ stand for the two roots. Graphical analysis reveals $\varepsilon_{1}=\frac{\left(a-c_{i}\right)\left[8+2 \theta^{2}-10 \theta^{4}-\sqrt{(1+\theta)\left(4+5 \theta^{2}\right)\left(-8+12 \theta-3 \theta^{2}+17 \theta^{3}\right)}\right]}{2(1+\theta)\left(4+5 \theta^{2}\right)}<\widehat{\varepsilon}$. Therefore, collusive licensing results in a higher welfare level than no licensing for $\varepsilon \geq \varepsilon_{2}=\varepsilon^{T P T N 3}$.

For $\varepsilon \geq \widetilde{\varepsilon}$, we have:

$$
W^{T P T}-W^{N}=\frac{\left(a-c_{i}\right)^{2}\left(3-2 \theta+2 \theta^{2}-3 \theta^{3}\right)}{2(1+\theta)\left(4+5 \theta^{2}\right)}
$$

which is positive for $\theta \in[0,1)$.

\section{H Proof of Lemma 3}

For $0 \leq \varepsilon<\varepsilon^{r}$, we have:

$$
W^{R}-W^{C}=\frac{2\left(a-c_{i}\right)^{2} E \theta(4-3 \theta)-4\left(a-c_{i}\right) \varepsilon E\left(2-\theta^{2}\right)-\varepsilon^{2}\left(2-\theta^{2}\right)^{2}\left(4+5 \theta^{2}\right)}{8\left(4-5 \theta^{2}+\theta^{4}\right)^{2}}
$$

where $E=(1+\theta)(1-\theta)^{2}(2+\theta)^{2}$. This is a concave quadratic function of $\varepsilon$ and its roots are $\varepsilon=\frac{\left(a-c_{i}\right)(1-\theta)\left[2\left(1-\theta^{2}\right)(2+\theta)^{2} \pm\left(4-\theta^{2}\right) \sqrt{2\left(2+8 \theta+5 \theta^{2}+\theta^{3}+2 \theta^{4}\right)}\right]}{\left(-2+\theta^{2}\right)\left(4+5 \theta^{2}\right)}$. Since the positive root is less than $\varepsilon^{r}$, welfare under royalty licensing is greater than welfare under collusive licensing for $\varepsilon \leq \varepsilon^{R C}=\frac{\left(a-c_{i}\right)(1-\theta)\left[2\left(1-\theta^{2}\right)(2+\theta)^{2}-\left(4-\theta^{2}\right) \sqrt{2\left(2+8 \theta+5 \theta^{2}+\theta^{3}+2 \theta^{4}\right)}\right]}{\left(-2+\theta^{2}\right)\left(4+5 \theta^{2}\right)}$.

For $\varepsilon \geq \varepsilon^{r}$, we have:

$$
W^{R}-W^{C}=-\frac{\left(a-c_{i}\right)^{2}\left(80-48 \theta-12 \theta^{2}-16 \theta^{3}-5 \theta^{4}+\theta^{5}\right)}{8(1+\theta)\left(8+\theta^{2}\right)^{2}}
$$

which is less than zero for $\theta \in[0,1)$. 


\section{Proof of Lemma 4}

For $0 \leq \varepsilon<\varepsilon^{t p t}$, the value for $W^{T P T}-W^{C}$ is equal to the value for $W^{R}-W^{C}$ in the interval $0 \leq \varepsilon<\varepsilon^{r}$. This is a concave quadratic function of $\varepsilon$ and its roots are $\varepsilon=\frac{\left(a-c_{i}\right)(1-\theta)\left[2\left(1-\theta^{2}\right)(2+\theta)^{2} \pm\left(4-\theta^{2}\right) \sqrt{2\left(2+8 \theta+5 \theta^{2}+\theta^{3}+2 \theta^{4}\right)}\right]}{\left(-2+\theta^{2}\right)\left(4+5 \theta^{2}\right)}$. Since the positive root is greater than $\varepsilon^{t p t}$, welfare under two-part tariff licensing is greater than welfare under collusive licensing for $\varepsilon \leq \varepsilon^{t p t}$.

For $\varepsilon \geq \varepsilon^{t p t}, W^{T P T}$ and $W^{C}$ are both independent of the magnitude of $\varepsilon$. We have:

$$
W^{T P T}-W^{C}=\frac{\left(a-c_{i}\right)^{2} \theta(1-\theta)(4-3 \theta)}{8(1+\theta)\left(4+5 \theta^{2}\right)}
$$

which proves to be nonnegative for $\theta \in[0,1)$.

\section{J Proof of Lemma 5}

For $0 \leq \varepsilon<\widehat{\varepsilon}$, we have:

$$
W^{C}-W^{N}=-\frac{\left(a-c_{i}\right)^{2} D \theta(4-3 \theta)-4\left(a-c_{i}\right) \varepsilon D(3-2 \theta)+2 \varepsilon^{2}\left(12-9 \theta^{2}+2 \theta^{4}\right)}{4\left(1-\theta^{2}\right)\left(4-\theta^{2}\right)^{2}}
$$

where $D=(1-\theta)(2+\theta)^{2}$. This is a concave quadratic function of $\varepsilon$. Its roots are given by $\varepsilon=\frac{\left(a-c_{i}\right)(2+\theta)\left[2(1-\theta)(2+\theta)(3-2 \theta) \pm(2-\theta) \sqrt{-2\left(-18+36 \theta+\theta^{2}-27 \theta^{3}+2 \theta^{4}+6 \theta^{5}\right)}\right]}{24-18 \theta^{2}+4 \theta^{4}}$. Let $\varepsilon^{C N 1}$ and $\varepsilon^{C N 2}$ represent the two roots. Graphical analysis reveals that collusive licensing results in a higher welfare level than no licensing for $\varepsilon^{C N 1} \leq \varepsilon \leq \min \left\{\varepsilon^{C N 2}, \widehat{\varepsilon}\right\}$.

For $\widehat{\varepsilon} \leq \varepsilon<\widetilde{\varepsilon}$, we have:

$$
W^{C}-W^{N}=\frac{3\left(a-c_{i}\right)^{2}}{4(1+\theta)}+\frac{\left(a-c_{i}-\varepsilon\right)\left[\left(a-c_{i}\right)(1-2 \theta)-\varepsilon\right]}{2 \theta^{2}}
$$

$W^{C}-W^{N}$ is a convex quadratic function of $\varepsilon$. Its roots are $\varepsilon=\frac{\left(a-c_{i}\right)\left[2\left(1-\theta^{2}\right) \pm \theta \sqrt{2\left(-1+\theta+2 \theta^{2}\right)}\right]}{2(1+\theta)}$. Let $\varepsilon_{1}$ and $\varepsilon_{2}$ stand for the two roots. Graphical comparison of the various $\varepsilon$ values reveals that $\widehat{\varepsilon}>\varepsilon_{1}=\frac{\left(a-c_{i}\right)\left[2\left(1-\theta^{2}\right)-\theta \sqrt{2\left(-1+\theta+2 \theta^{2}\right)}\right]}{2(1+\theta)}$. Therefore, collusive licensing results in a higher welfare level than no licensing for $\varepsilon \geq \varepsilon_{2}=\varepsilon^{C N 3}$.

For $\varepsilon \geq \widetilde{\varepsilon}$, we have:

$$
W^{C}-W^{N}=\frac{3\left(a-c_{i}\right)^{2}(1-\theta)}{8(1+\theta)}
$$

which is positive for $\theta \in[0,1)$. 


\section{K Proof of Lemma 6}

Consider first $W^{F}$ and $W^{N}$. For $0 \leq \varepsilon<\widehat{\varepsilon}$, we have:

$$
W^{F}-W^{N}=\frac{\varepsilon\left[2\left(a-c_{i}\right)(1-\theta)(2+\theta)^{2}(3-2 \theta)-\varepsilon\left(12-9 \theta^{2}+2 \theta^{4}\right)\right]}{\left(1-\theta^{2}\right)\left(4-\theta^{2}\right)^{2}}
$$

It is sufficient to show that the term inside the brackets is positive. Substituting for $\widehat{\varepsilon}$ in $\varepsilon<\widehat{\varepsilon}$, we get $\varepsilon\left(2-\theta^{2}\right)<\left(a-c_{i}\right)(1-\theta)(2+\theta)$. Multiplying both sides by $2(2+\theta)(3-2 \theta)$ gives us $2 \varepsilon\left(2-\theta^{2}\right)(2+\theta)(3-2 \theta)<2\left(a-c_{i}\right)(1-\theta)(2+\theta)^{2}(3-2 \theta)$. Since $\varepsilon\left(12-9 \theta^{2}+2 \theta^{4}\right)$ is smaller than the left hand side of this expression, we observe that the term inside the brackets in the expression for $W^{F}-W^{N}$ is positive.

For $\widehat{\varepsilon} \leq \varepsilon<\widetilde{\varepsilon}$, we have:

$$
W^{F}-W^{N}=\frac{\left(a-c_{i}\right)^{2}(3-2 \theta)}{(1+\theta)(2-\theta)^{2}}+\frac{\left(a-c_{i}-\varepsilon\right)\left[\left(a-c_{i}\right)(1-2 \theta)-\varepsilon\right]}{2 \theta^{2}}
$$

Taking the derivative with respect to $\varepsilon$ yields $\frac{\varepsilon-\left(a-c_{i}\right)(1-\theta)}{\theta^{2}}$, which is always positive for $\widehat{\varepsilon} \leq \varepsilon<\widetilde{\varepsilon}$. Evaluating $W^{F}-W^{N}$ at the lower bound of this interval shows that it is positive for $\varepsilon=\widehat{\varepsilon}$. Therefore, $W^{F}-W^{N}$ is always positive in this interval.

For $\varepsilon \geq \widetilde{\varepsilon}$, we have:

$$
W^{F}-W^{N}=\frac{\left(a-c_{i}\right)^{2}\left(12-16 \theta+9 \theta^{2}-3 \theta^{3}\right)}{8(1+\theta)(2-\theta)^{2}}
$$

This expression is positive for $\theta \in[0,1)$.

In order to compare $W^{F}$ and $W^{C}$ note that

$$
W^{F}-W^{C}=\frac{\left(a-c_{i}\right)^{2} \theta(4-3 \theta)}{4(1+\theta)(2-\theta)^{2}} .
$$

This expression does not depend on $\varepsilon$ and is nonnegative for $\theta \in[0,1)$.

\section{Proof of Proposition 6}

From Lemma 3, we know that $W^{R} \geq W^{C}$ if and only if $\varepsilon \leq \varepsilon^{R C}$. Therefore, for $\varepsilon>\varepsilon^{R C}$, the government should decide when to allow collusive licensing. Combining Proposition 2, Lemma 1, Lemma 5, and Lemma 3 gives us the exact areas where collusive licensing should be allowed and where royalty licensing should not be allowed. Specifically, we have: 
(i) For $0 \leq \varepsilon<\varepsilon^{r}$, the government should allow royalty licensing iff $\varepsilon \leq \varepsilon^{R C}$ and $\varepsilon \leq \varepsilon^{R N 1}$. The government should allow collusive licensing iff $\varepsilon>\varepsilon^{R C}$ and $\varepsilon \geq \varepsilon^{C N 1}$.

(ii) For $\varepsilon^{r} \leq \varepsilon<\widehat{\varepsilon}$, the government should allow collusive licensing iff $\varepsilon^{C N 1} \leq \varepsilon \leq \varepsilon^{C N 2}$.

(iii) For $\widehat{\varepsilon} \leq \varepsilon<\widetilde{\varepsilon}$, the government should allow collusive licensing iff $\varepsilon \geq \varepsilon^{C N 3}$.

(iv) For $\varepsilon \geq \widetilde{\varepsilon}$, the government should always allow collusive licensing.

\section{Proof of Proposition 7}

From Lemma 4, we know that $W^{T P T} \geq W^{C}$ always holds. The main question is, given that $W^{T P T} \geq W^{N}$ does not always hold, whether the government should restrict the firms to do fixed fee or royalty licensing only in cases when $W^{T P T}<W^{N}$. From Figure 3 we can see that $W^{T P T}<W^{N}$ implies $W^{R}<W^{N}$. Therefore, since it is always the case that $W^{F} \geq W^{N}$, it is socially desirable to have fixed fee licensing when $W^{T P T}<W^{N}$. In this region, whether there will be any technology transfers or not depends on the firms' incentives, which are given in Proposition 3.

Combining Proposition 3, Proposition 5, Lemma 6, Lemma 2, Lemma 5, and Lemma 4 reveals the exact areas where two-part tariff licensing should not be allowed and where there will be no technology transfers:

(i) For $0 \leq \varepsilon<\varepsilon^{t p t}$, the government should always allow two-part tariff licensing.

(ii) For $\varepsilon^{t p t} \leq \varepsilon<\widehat{\varepsilon}$, the government should allow two-part tariff licensing iff $\varepsilon^{T P T N 1} \leq \varepsilon \leq$ $\varepsilon^{T P T N 2}$. The government should allow the firms to do fixed fee licensing only iff $\varepsilon<\varepsilon^{T P T N 1}$ and $\varepsilon>\varepsilon^{T P T N 2}$. We know from Proposition 3 that the firms will choose to do fixed fee licensing in that region iff $\varepsilon \leq \varepsilon^{F N 1}$.

(iii) For $\widehat{\varepsilon} \leq \varepsilon<\widetilde{\varepsilon}$, the government should not allow two-part tariff licensing iff $\varepsilon<$ $\varepsilon^{T P T N 3}$. Since royalty licensing will not be allowed in the same region either, the firms have the option of doing fixed fee licensing only. However, given Proposition 3, they will choose not to have any technology transfers.

(iv) For $\varepsilon \geq \widetilde{\varepsilon}$, the government should always allow two-part tariff licensing.

\section{N Proof of Proposition 8}

From Lemma 6, we know that $W^{F} \geq W^{N}$ and $W^{F} \geq W^{C}$ always hold. The question is whether the government should allow collusive licensing in cases when the firms will not do any fixed fee licensing. Combining Proposition 3 and Lemma 5 gives us the exact areas 
where collusive licensing should be allowed and where there will be no technology transfers. Specifically, we have:

(i) For $0 \leq \varepsilon<\widehat{\varepsilon}$, the firms choose not to do any fixed fee licensing iff $\varepsilon>\varepsilon^{F N 1}$. The government should allow collusive licensing iff $\varepsilon>\varepsilon^{F N 1}$ and $\varepsilon \leq \varepsilon^{C N 2}$.

(ii) For $\widehat{\varepsilon} \leq \varepsilon<\widetilde{\varepsilon}$, the firms choose not to do any fixed fee licensing iff $\varepsilon>\varepsilon^{F N 2}$. The government should allow collusive licensing iff $\varepsilon>\varepsilon^{F N 2}$ and $\varepsilon \geq \varepsilon^{C N 3}$.

(iii) For $\varepsilon \geq \widetilde{\varepsilon}$, the firms choose to do any fixed fee licensing iff $\theta \leq 0.61$. The government should allow collusive licensing iff $\theta>0.61$. 


\section{References}

[1] Anand, B. N. and T. Khanna. (2000), "The Structure of Licensing Contracts," Journal of Industrial Economics, 48, 103-135.

[2] Arora, A. and A. Fosfuri. (1998), "Licensing in the Chemical Industry," Carnegie Mellon University, Working Paper 1998-24.

[3] Arora, A. and A. Fosfuri. (2003), "Licensing the Market for Technology," Journal of Economic Behavior and Organization, 52, 277-295.

[4] Beggs, A. W. (1992), "The Licensing of Patents under Asymmetric Information," International Journal of Industrial Organization, 10, 171-191.

[5] Choi, J. P. (2001), "Technology Transfer with Moral Hazard," International Journal of Industrial Organization, 19, 249-266.

[6] Degnan, S. A. (1999), "The Licensing Payoff from U.S. R\&D," Research Technology Management, 42, 22-25.

[7] Erkal, N. (2002), "Essays on Innovation, Disclosure, and Product Choice," Ph.D. Thesis, Department of Economics, University of Maryland, College Park, USA.

[8] Erkal, N. (2004), "Optimal Licensing Policy in Differentiated Industries," University of Melbourne, Department of Economics, Research Paper \#894.

[9] Eswaran, M. (1994), "Licensees as Entry Barriers," Canadian Journal of Economics, 27, 673-688.

[10] Fauli-Oller, R. and J. Sandonis. (2002), "Welfare Reducing Licensing," Games and Economic Behavior, 41, 192-205.

[11] Fauli-Oller, R. and J. Sandonis. (2003), "To Merge or to License: Implications for Competition Policy," International Journal of Industrial Organization, 21, 655-672.

[12] Gallini, N. T. (1984), "Deterrence through Market Sharing: A Strategic Incentive for Licensing," American Economic Review, 74, 931-941.

[13] Gallini, N. T. and B. D. Wright. (1990), "Technology Transfer under Asymmetric Information," Rand Journal of Economics, 21, 147-160. 
[14] Gilbert, R. and C. Shapiro. (1997), "Antitrust Issues in the Licensing of Intellectual Property: The Nine No-No's Meet the Nineties," Brookings Papers on Economic Activity: Microeconomics, 283-349.

[15] Grindley, P. C. and J. A. Nickerson. (1996), "Licensing in the Chemical Industry: A Case Study," in Licensing Strategy, R. Parr and P. Sullivan eds., John Wiley \& Sons, New York.

[16] Grindley, P. C. and D. J. Teece. (1997), "Managing Intellectual Capital: Licensing and Cross-Licensing in Semiconductors and Electronics," California Management Review, 39, 8-41.

[17] Hollis, A. (2002), "The Strategic Implications of Learning by Doing," International Journal of the Economics of Business, 92, 157-174.

[18] Kamien, M. I. (1992), "Patent Licensing," in Handbook of Game Theory with Economic

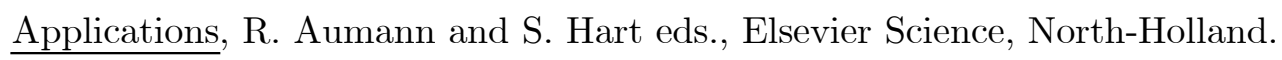

[19] Kamien, M. I., S. S. Oren, and Y. Tauman. (1992), "Optimal Licensing of Cost-Reducing Innovation," Journal of Mathematical Economics, 21, 483-508.

[20] Kamien, M. I. and Y. Tauman. (1986), "Fees versus Royalties and the Private Value of a Patent," Quarterly Journal of Economics, 101, 471-491.

[21] Kamien, M. I. and Y. Tauman. (2002), "Patent Licensing: The Inside Story," The Manchester School, 70, 7-15.

[22] Katz, M. L. and C. Shapiro. (1985), "On the Licensing of Innovations," Rand Journal of Economics, 16, 504-520.

[23] Katz, M. L. and C. Shapiro. (1986), "How to License Intangible Property," Quarterly Journal of Economics, 101, 567-590.

[24] Lin, P. (1996), "Fixed-Fee Licensing of Innovations and Collusion," Journal of Industrial Economics, 44, 443-449.

[25] Macho-Stadler, I., X. Martinez-Giralt, and J. D. Perez-Castrillo. (1996), "The Role of Information in Licensing Contract Design," Research Policy, 25, 43-57. 
[26] Marjit, S. (1990), "On a Non-Cooperative Theory of Technology Transfer," Economics Letters, 33, 293-298.

[27] Muto, S. (1993), "On Licensing Policies in Bertrand Competition," Games and Economic Behavior, 5, 257-267.

[28] Poddar, S. and U. B. Sinha. (2004), "On Patent Licensing in Spatial Competition," Economic Record, 80, 208-218.

[29] Rockett, K. E. (1990a), "Choosing the Competition and Patent Licensing," Rand Journal of Economics, 21, 161-172.

[30] Rockett, K. E. (1990b), "The Quality of Licensed Technology," International Journal of Industrial Organization, 8, 559-574.

[31] Rostoker, M. (1984), “A Survey of Corporate Licensing," IDEA, 24, 59-92.

[32] Shapiro, C. (1985), "Patent Licensing and R\&D Rivalry," American Economic Review, $75,25-30$.

[33] Singh, N. and X. Vives. (1984), "Price and Quantity Competition in a Differentiated Duopoly," Rand Journal of Economics, 15, 546-554.

[34] U.S. Department of Justice and Federal Trade Commission. 1995. "Antitrust Guidelines for the Licensing of Intellectual Property," http://www.usdoj.gov/atr/public/guidelines/ipguide/htm.

[35] Wang, X. H. (1998), "Fee Versus Royalty Licensing in a Cournot Duopoly Model," Economics Letters, 60, 55-62.

[36] Wang, X. H. (2002), "Fee versus Royalty Licensing in a Differentiated Cournot Duopoly," Journal of Economics and Business, 54, 253-266.

[37] Wang, X. H. and B. Z. Yang. (1999), "On Licensing under Bertrand Competition," Australian Economic Papers, 38, 106-119. 